\title{
International Contagion Effects from the Russian Crisis and the LTCM Near-Collapse
}

\author{
Prepared by Mardi Dungey, Renée Fry, Brenda González-Hermosillo, and Vance Martin ${ }^{1}$
}

January 2002

\begin{abstract}
We examine empirically the episode of extraordinary turbulence in global financial markets during 1998. The analysis focuses on the market assessment of credit risk captured by daily movements in bond spreads for twelve countries. A dynamic latent factor model is estimated using indirect inference to quantify the effects of unanticipated shocks across borders or "contagion," controlling for common global shocks, country-specific shocks and regional factors. The results show that there were substantial international contagion effects resulting from both the Russian and the LTCM crises. The proportion of volatility explained by contagion is not necessarily larger in developing than in developed nations.
\end{abstract}

JEL Classification Numbers: C33, E44, F34

Keywords: Financial Crises, Contagion Effects, International Spillovers, Russia, LTCM Authors’ E-Mail Address: Mardi.Dungey@anu.edu.au; ra.fry@ qut.edu.au; bgonzalez@imf.org; vance@myriad.its.unimelb.edu.au

\footnotetext{
${ }^{1}$ Australian National University, Queensland University of Technology, International Monetary Fund and University of Melbourne, respectively. Part of the research for this paper was undertaken when Mardi Dungey was a visiting scholar at the IMF Institute. Mardi Dungey and Vance Martin acknowledge funding from ARC grant no. A00001350. The authors are grateful to Reza Vaez-Zadeh and seminar participants at the IMF for helpful comments. The views expressed in this paper are those of the authors and do not necessarily represent those of the International Monetary Fund.
} 


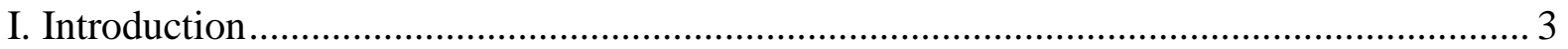

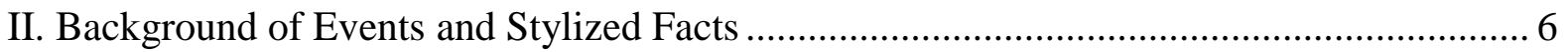

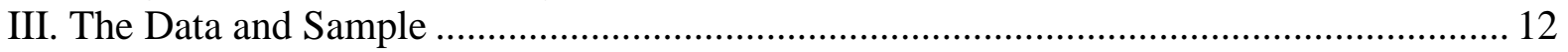

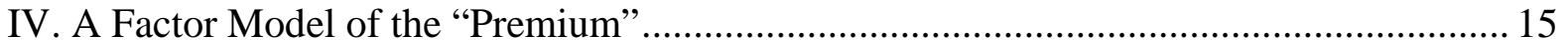

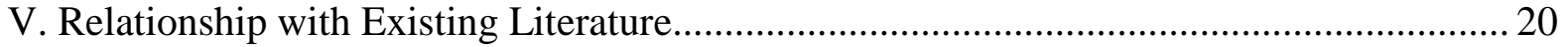

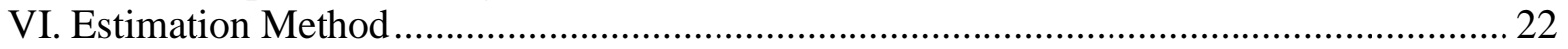

VII. Empirical Results .......................................................................................... 26

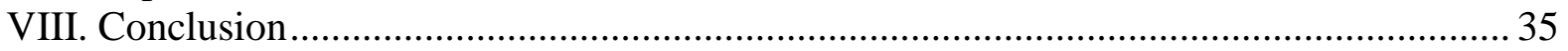

Text Tables

1. Univariate GARCH $(1,1)$ Parameter Estimates

2. Volatility Decomposition with Contagion Effects from Russia (in percent)

3. Volatility Decomposition with Contagion Effects from Russia (in basis points)

4. Volatility Decompostion with Contagion Effects from Russia and the United States (in percent)

5. Volatility Decomposition with Contagion Effects from Russia and the United States (in basis points)

Figures

1. Bond Spreads, January 1997-May 1999

2. Bond Spreads in First Differences, January 1997-May 1999

3. Bond Spreads, May 1998-December 1998

4. Bond Spreads in First Differences, May 1998-December 1998

5. Volatility Decomposition with Contagion from Russia

6. Volatility Decomposition with Contagion Effects from Russia and the United States

7. Contagion in Basis Points - The Smaller Contributions

8. Contagion in Basis Points - The Larger Contributions

Appendices

1. Data Definitions and Sources

Data Used for Empirical Estimation

2. Descriptive Statistics

Unit Root and Cointegration Tests 


\section{INTRODUCTION}

Since the mid-1990s, international financial markets have experienced several episodes of distress. The major financial crises observed in recent years are from diverse regions, and include Mexico in December 1994, Asia beginning in July 1997, Russia in August 1998, the near-collapse of the U.S. hedge fund Long-Term Capital Management (LTCM) in September 1998, Brazil towards the end of 1998 and early 1999, and more recently, Turkey and Argentina in 2001.

During these crises, financial market commentators and participants have often been concerned about the linkages between countries and financial markets, and the possibility that a crisis will spillover and lead to extreme volatility elsewhere in the world's financial markets. The anecdotal evidence suggests that the impact of the recent financial crises on other financial market asset classes and centres differs across crises and countries. For example, the Russian/LTCM crises during August-September 1998 were characterized by increased volatility in global securities markets. A reassessment of credit and sovereign risks during this period led to large jumps in credit and liquidity spreads and in risk premia in both emerging and advanced economies. These effects have been associated with increased risk aversion during this period (e.g., JP Morgan (1999) and Kumar and Persaud (2001)). In contrast, the international spillover effects of other recent financial crises (e.g., the Mexican and Asian crises) appear to have been limited to a given region(s) or to emerging markets only.

This paper examines the transmission of the Russian crisis and the LTCM nearcollapse to other countries. This particular episode of financial distress is of special interest because it not only affected financial markets in emerging countries, but also in many advanced economies. One key characteristic of the Russian/LTCM crises is that the risks of default were mainly on tradable securities, while in other recent crises (e.g. Asia) the trigger was the risk of default on bank loans. According to market participants, the Russian bond default and the subsequent near-collapse of LTCM was "the worst crisis" in recent times (Bank for International Settlements (1999)). The duration of the LTCM crisis turned out to be relatively short, spanning only a few weeks, possibly due to the Federal Reserve's aggressive easing of monetary policy during the period. Nonetheless, the effects of the 1998 crises were felt dramatically across global financial markets. Although lending activity by banks appeared relatively unaffected, many currency markets were jittery and global security markets seized-up. During this period, risk premiums as captured by the spreads between long-term sovereign bonds issued in international markets by emerging markets, and longterm corporate bonds issued in advanced economies, vis-à- vis comparable risk-free benchmarks, reached extraordinarily high levels in both developing and advanced economies. Investors switched to highly liquid assets, demanding sharply higher premiums even for riskfree securities with lower liquidity (e.g., spreads between the 29-year U.S. Treasury bond and the more liquid "on-the-run" 30-year U.S. Treasury bond reached historically high levels).

Most analyses on recent financial crises have focused on currency, banking or equity markets. There is little by the way of academic literature on the spread of crises through the 
international bond markets. This is in part because bond markets in many developing countries have lacked liquidity, and because a consistent and comprehensive historical database on bond spreads is difficult to construct for the early periods. Bond markets may have also enticed less interest because, compared with equity and currency markets, global bond markets appeared to be relatively stable during the Asian crisis. One of the advantages of examining bond spreads is that they reflect the risk premium that investors assign to prospective borrowers, either because of the perceived creditworthiness of borrowers or due to the willingness of lenders to take on risk. Of course, bond spreads also respond to the degree of liquidity in the market, although all of these factors seem to be entangled during crisis episodes. One interpretation of examining the effects of the Russian crisis and the LTCM shock separately is that the former affected credit risk concerns while the latter worked as a global liquidity shock.

This study attempts to shed light on several questions. Was the volatility in bond market spreads a reflection of the long run relationships between economies, or was it the spillover of unanticipated events from Russia and the United States to the other economies, and therefore contagion? What evidence is there that the Russian default affected only emerging markets while the LTCM problems mainly affected matured markets, as suggested in Bank for International Settlements (1999)? ${ }^{2}$ Further, is there evidence that developing markets are more likely to be affected by contagion than developed markets, as maintained, for example, by Bae, Karyoli and Stultz (2000) for equity markets? Finally, were the Russian crisis and the LTCM near-default independent events, or did the two shocks reinforce each other in terms of their impact on global financial markets?

The approach taken in this paper is to examine the daily behavior of the risk premia for 12 countries among several regions of the world. The selection of the sample is representative of countries from each key region of the world for whom consistent data could be assembled, and limited to a sample which could be reasonably handled by the estimation technique. Thus, the sample includes: Argentina, Brazil and Mexico from Latin America; Indonesia, South Korea and Thailand from Asia; Bulgaria, Poland and Russia from Eastern Europe; and the Netherlands, the United Kingdom and the United States as representative industrial countries in Europe and North America. The period of study encompasses February to end-December $1998 .^{3}$

\footnotetext{
${ }^{2}$ Some researchers examining international spillover effects during 1998 only focus on the Russian crisis and overlook the LTCM shock (e.g., Forbes (2000)).

${ }^{3}$ Malaysia was excluded from the formal analysis because of important gaps in the data and potential biases from capital controls in the period. Canada was excluded in this version of the paper because Canadian markets tend to move closely with U.S. markets. The period of analysis was selected to avoid important gaps in the data for key countries, such as Thailand before 1998, and to limit this study to the financial crises of 1998.
} 
Specifically, a latent factor model of the spreads in the bond market is developed to examine the effects of unanticipated movements in the Russian and U.S. markets on other markets around the world. ${ }^{4}$ The bond spreads are decomposed into a set of latent factors, identified as common shocks and country-specific shocks. The latent factors themselves are specified to evolve according to unit root autoregressive processes, or are stationary. GARCH characteristics are also modelled to reconcile the model with the observed features of financial data. The origins of the model can be found in papers such as Diebold and Nerlove (1989) and Mahieu and Schotman (1994). More recently, Dungey, Martin and Pagan (2000) demonstrate how this type of model can be identified and estimated using indirect estimation techniques. We adopt a similar approach here, although the model specified here is more complex. Dungey, Martin and Pagan (2000) show how the volatility in international long bond spreads can be decomposed into contributions due to three factors, where the common factor evolves as a GARCH $(1,1)$ process. Here we introduce effects of the transmission of unanticipated country-specific shocks in one country on other countries. In common with a substantial part of the literature on this subject, we refer to this effect as the contagion effect.

The estimation technique itself is computationally intensive, and involves repeated simulations to obtain the best parameter estimates. The results show that there is discernible contagion from both the Russian crisis and the LTCM near-collapse to other economies in the sample. The orders of magnitude vary between 0 and 17 percent of total volatility of bond market spreads attributed to contagion. These results provide mixed evidence on whether contagion is more substantial for developed or developing markets. On the one hand, countries such as Poland, Brazil and Thailand were more affected by contagion than the United Kingdom but, on the other hand, Indonesia, Mexico and South Korea were less affected by contagion than the United States and the Netherlands. However, when the results are scaled by the level of volatility evident in the sample, it is clear that in general the magnitude of contagion effects, as measured in basis points, is relatively greater for developing than developed countries.

The remainder of this paper is organized as follows. Section II reviews the background and the stylized facts of the data, followed by a discussion of the data characteristics and the sample period in Section III. The model of contagion used in this paper is given in Section IV, and is then related to the existing literature on contagion in Section V. In Section VI the estimation method is discussed and Section VII details the empirical results. Section VIII concludes.

\footnotetext{
${ }^{4}$ The advantage of this technique is that it is possible to identify and quantify these effects without resorting to ad hoc identification of the pertinent fundamentals; see, for example, Eichengreen, Rose and Wyplosz (1996), Glick and Rose (1999), Forbes and Rigobon (1999), for a discussion of these issues.
} 


\section{BACKGROUND OF EVENTS AND STYLIZED FACTS}

During the Asian crisis, the turmoil which began with the devaluation of the Thai baht in July 1997 quickly precipitated declines in currencies and equities in the region and in other developing markets. However, the effects on the risk premia of the international bonds issued by emerging countries were rather limited. Apart from the relatively short period of turmoil in global financial markets resulting from the speculative attack on Hong Kong on October 27, 1997, bond spreads were relatively stable in non-Asian countries during the second half of 1997 (see Figures 1 and 2).

After a period of relative calm in international bond markets during the first part of 1998, a shock was felt on August 17, 1998 when Russia announced a de facto devaluation by widening the trading band of the ruble. Russia also declared its intention to restructure all official domestic currency debt obligations falling due to the end of 1999 and imposed a 90day moratorium on the repayment of private external debt. The period in the lead up to these events also held evidence of stress. ${ }^{5}$

The Russian default appears to have led to a reassessment of credit and sovereign risks across global financial markets, evidenced by large jumps on liquidity spreads and risk premia. The jump in bond spreads and the increased volatility in global bond markets resulting from the Russian moratorium was felt in a number of emerging markets and also in advanced economies (see Figures 1-4).

A few weeks after the Russian crisis was unveiled, news reached financial markets on September 23, 1998 about the financial scheme that was being put together to rescue the U.S. hedge fund LTCM. The investment strategies of LTCM had been largely based on betting on "normal" volatilities and spreads between closely related securities, some of which seemed to have changed in the aftermath of the Russian crisis. In retrospect, it is now publicly known that LTCM lost more than 50 percent of its end-December 1997 capital by the end of August 1998 (Jorion (2000)). With assets still at $\$ 126$ billion, the leverage ratio (or the ratio of assets-to-capital) had increased from 28-to-1 to 55-to-1 during the same period. The potential effect of LTCM collapsing was such that the New York Federal Reserve felt compelled to act. On September 23, it organized a bailout of LTCM, encouraging 14 banks to invest in the hedge fund for a stake in the firm to save it.

\footnotetext{
${ }^{5}$ See Kharas, Pinto and Ulatov (2001) for a discussion of the Russian crisis.
} 
Figure 1. Bond Spreads, January 1997-May $1999^{1}$ (basis points)
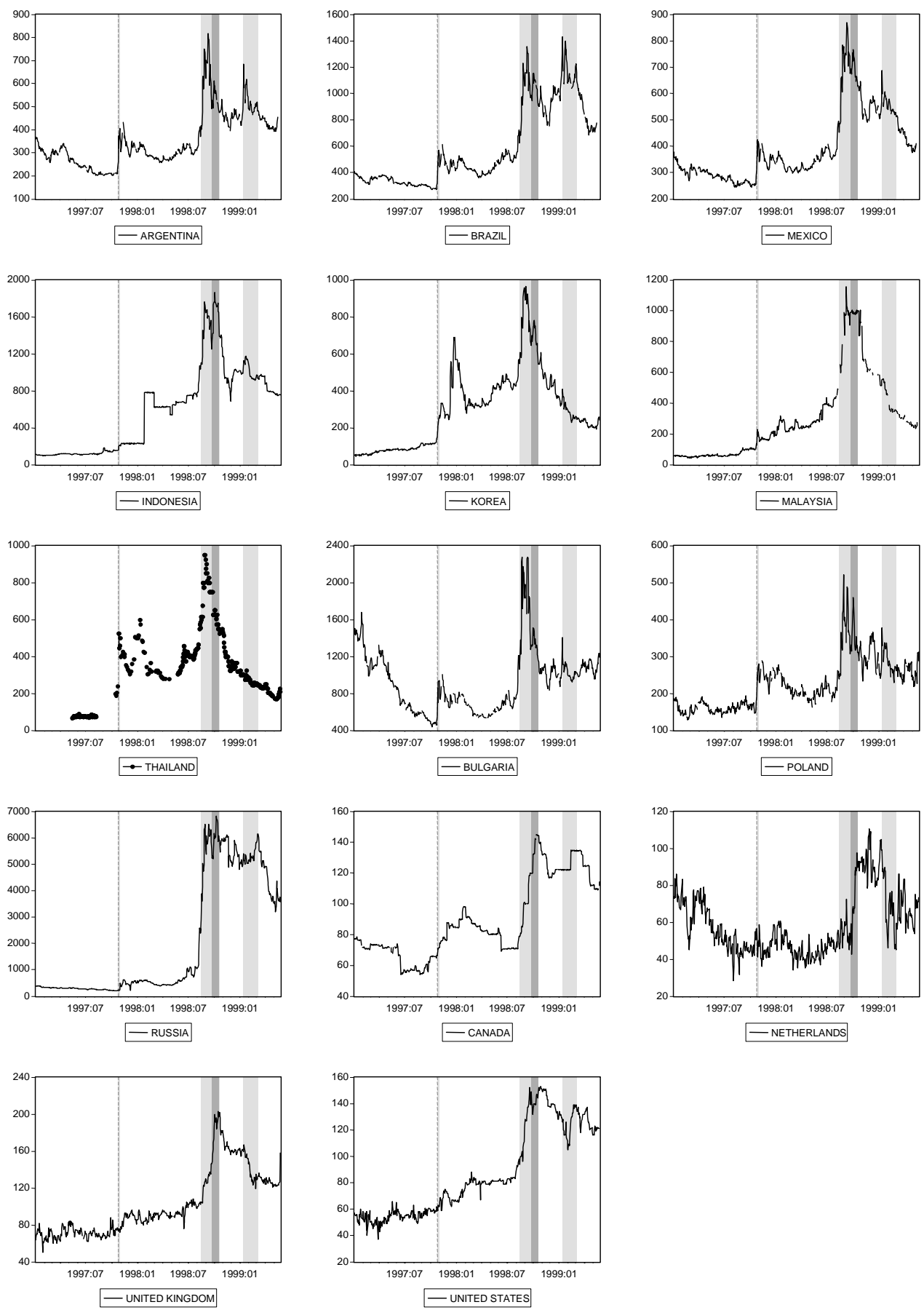

\footnotetext{
1 The shaded areas refer to episodes of crisis in international bond markets: the Hong Kong speculative attack on October 27, 1997; the Russian bond default on August 17, 1998; the bailout of LTCM orchestrated by the New York Federal Reserve on September 23, 1998; the inter-FOMC Fed interest rate cut on October 15, 1998 which signaled the beginning of the "end" of the LTCM crisis; and the Brazilian effective devaluation on January 13, 1999 followed by a few weeks of turmoil at the time when the central bank governor was replaced. Data Sources: U.S. Federal Reserve, Bloomberg, Scotia Capital and Credit Swiss First Boston.
} 
Figure 2. Bond Spreads in First Differences, January 1997-May $1999^{1}$ (basis points)
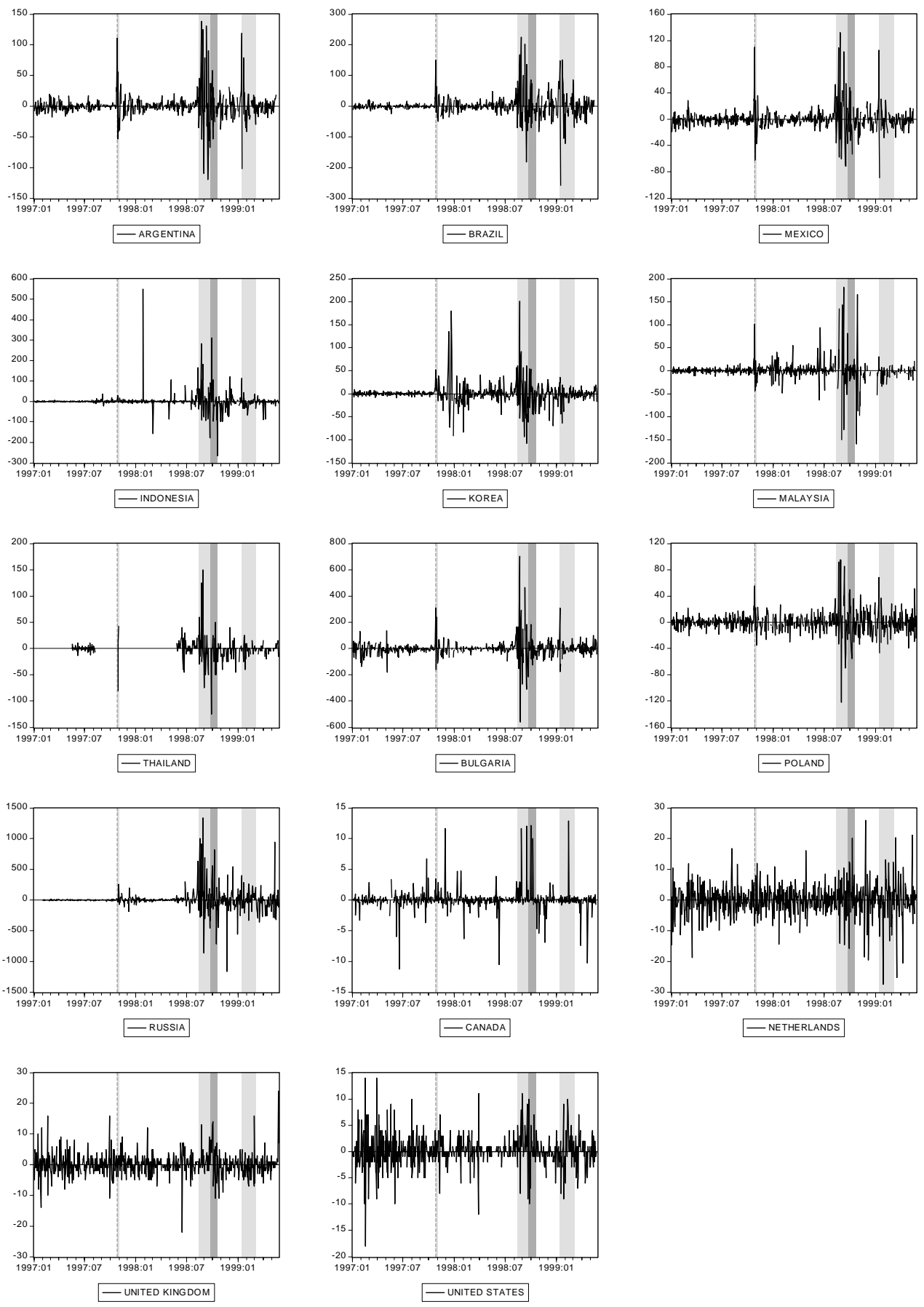

\footnotetext{
${ }^{1}$ The shaded areas refer to episodes of crisis in international bond markets: the Hong Kong speculative attack on October 27, 1997; the Russian bond default on August 17, 1998; the bailout of LTCM orchestrated by the New York Federal Reserve on September 23, 1998; the inter-FOMC Fed interest rate cut on October 15, 1998 which signaled the beginning of the "end" of the LTCM crisis; and the Brazilian effective devaluation on January 13, 1999 followed by a few weeks of turmoil at the time when the central bank governor was replaced. Data Sources: U.S. Federal Reserve, Bloomberg, Scotia Capital and Credit Swiss First Boston.
} 
Figure 3. Bond Spreads, May 1998-December $1998^{1}$

(basis points)
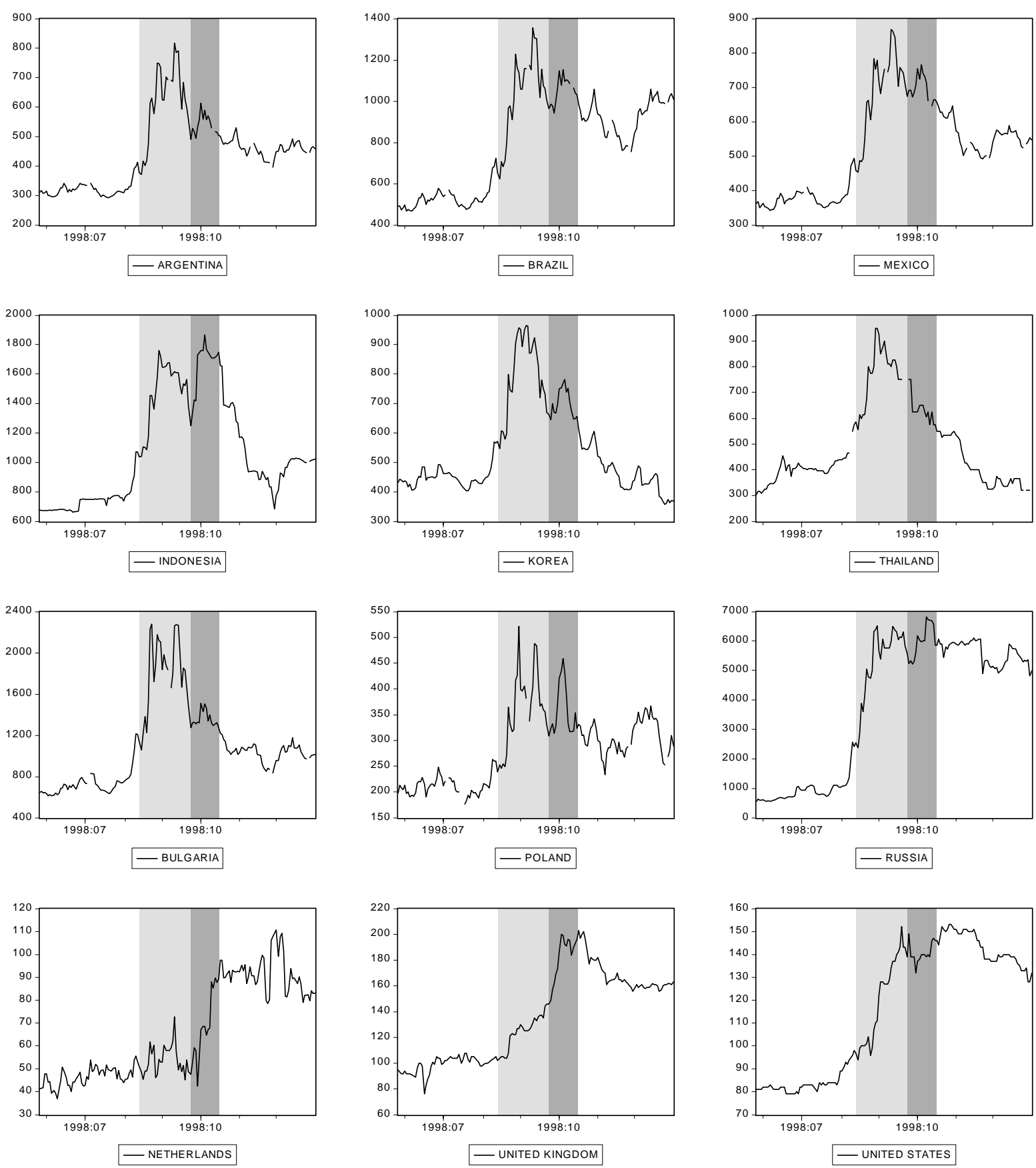

\footnotetext{
${ }^{1}$ The shaded areas refer to episodes of crisis in international bond markets during this period: the Russian bond default on August 17, 1998; the bailout of LTCM orchestrated by the New York Federal Reserve on September 23, 1998; and the inter-FOMC Fed interest rate cut on October 15, 1998 which signaled the beginning of the "end" of the LTCM crisis. Data Sources: U.S. Federal Reserve, Bloomberg, Scotia Capital and Credit Swiss First Boston.
} 
Figure 4. Bond Spreads in First Differences, May 1998-December $1998{ }^{1}$ (basis points)
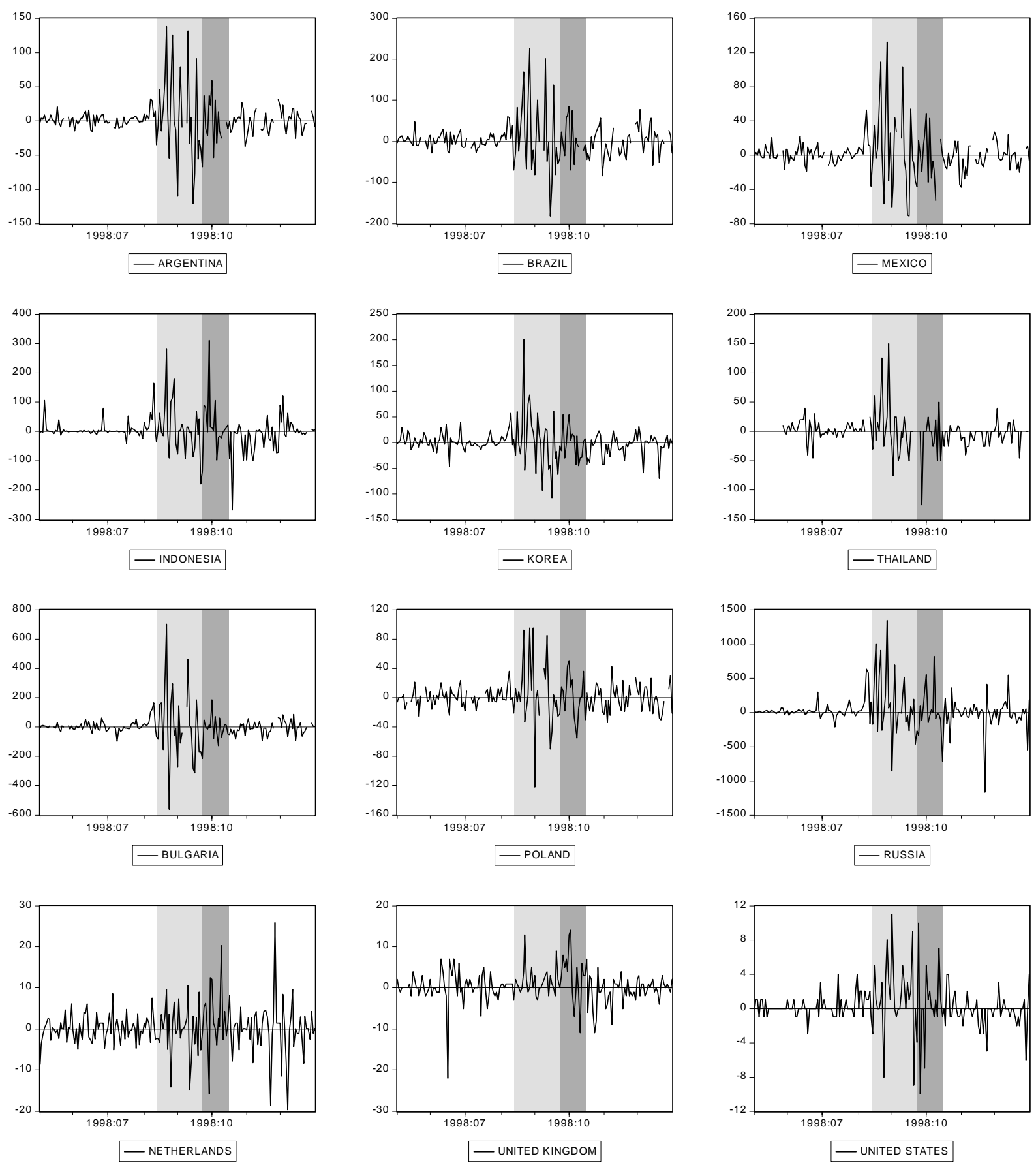

\footnotetext{
${ }^{1}$ The shaded areas refer to episodes of crisis in international bond markets during this period: the Russian bond default on August 17, 1998; the bailout of LTCM orchestrated by the New York Federal Reserve on September 23, 1998; and the inter-FOMC Fed interest rate cut on October 15, 1998 which signaled the beginning of the "end" of the LTCM crisis. Data Sources: U.S. Federal Reserve, Bloomberg, Scotia Capital and Credit Swiss First Boston.
} 
During this period of extreme volatility, the U.S. Federal Reserve cut interest rates aggressively in three steps between September 29 and November 17, 1998. One of these moves was a surprise inter-FOMC meeting cut on October 15 which, according to market participants (Bank for International Settlements (1999)), signaled the beginning of the abatement of financial constraints. ${ }^{6}$ The sharp easing in U.S. monetary policy was in part motivated by growing concerns that the U.S. economy was on the verge of experiencing a liquidity crash as bond spreads in the United States, and in other countries, had risen to exceptionally high levels. The Federal Reserve actions may have staved off a far more dramatic crisis. Based on interviews with market participants, the BIS Committee on the Global Financial System (Bank for International Settlements (1999), p. 40) noted that:

\section{"only a small number of market participants declined to characterize the 1998 crisis as 'exceptional.' Most interviewers mentioned that the events described [...] led to the worst crisis ever."}

Informal examination of the data for the second half of 1998 (Figures 3-4) seems to suggest that the Russian crisis had a substantial impact on all countries examined, both in advanced economies and emerging markets. Emerging economies appear to have been impacted, but the effects from the Russian crisis seem to have been also significant for the advanced economies. These results are confirmed by the empirical work in this paper reported in Section VII. The LTCM shock also appears to have had an impact on all the countries, with a relatively smaller hump experienced by most emerging countries relative to the effect of the Russian shock. The data seem to suggest that the Russian and the LTCM shocks were reinforcing in international financial markets since practically all markets experienced two jumps in their spreads: one following the Russian default (the first band in the figures) and another one following the announcement of the LTCM financial problems (the second band in the figures). Similarly, the fact that bond spreads began to rise in the United States following the Russian crisis and the Russian sovereign spread rose further in the aftermath of the LTCM crisis suggests that these two events may not have been totally independent.

The financial crisis during August-September 1998 marks a very interesting event because, unlike other recent financial crises, the shocks during this period seem to have been transmitted across countries with little in common-including countries that do not fit traditional explanations of contagion based on trade links, competitive devaluation or regional effects (see for example Lowell, Neu and Tong (1998), Goldstein (1998) for taxonomies of contagion). The crisis of 1998 affected countries as diverse as Russia and Brazil (e.g. Baig and Goldfajn (2000) argue that the Russian crisis precipitated the Brazilian crisis), and emerging and advanced economies. Furthermore, examining the crisis of 1998 is

\footnotetext{
${ }^{6}$ This otherwise arbitrary "end" to the crisis of 1998, is also supported by other findings in the literature (see, for example, Kumar and Persaud (2001)).
} 
particularly complex because of its relative brevity and the fact that not one but two seemingly separate shocks (the Russian default and the LTCM near-collapse) occurred within weeks of each other.

\section{The DATA AND SAMPLE}

Daily data for twelve representative countries were collected for the period February to December 1998 (Mexico, Argentina, Brazil, Indonesia, South Korea, Thailand, Bulgaria, Poland, Russia, the Netherlands, the United Kingdom and the United States). This sample period allows our estimation to incorporate a clear 'pre-crisis' period and the two crisis events of the Russian bond default and the LTCM near-default.

The data were collected to represent the spread of long-term debt over the appropriate risk-free yield for each country (see Appendix I for source descriptions and definitions). We label this spread as the 'premium' while recognizing that it does in fact reflect a myriad of factors, including the liquidity premium and the term structure of the yield curve. The choice of the risk free rate was specific to each long-term bond, because it depends at least in part on the currency of denomination of the bond issue. In the case of the emerging countries, sovereign bonds were issued in U.S. dollars, rather than in domestic currency, and hence the spread is calculated against the comparable maturity-matched U.S. Treasury bond rate. To the extent possible, the bonds selected for emerging markets were sovereign issues (rather than Brady) to reflect the true cost of new foreign capital. ${ }^{7}$ In the case of the advanced markets, which are able to issue international bonds in domestic currency, benchmark investment grade corporate bonds were compared to the corresponding risk-free Treasury bond in each country. ${ }^{8}$

Appendix I also details our methodology for dealing with missing observations. We chose to eliminate all the days in which we did not have a complete set of observations for all

\footnotetext{
${ }^{7}$ Brady bonds were introduced in 1989 in exchange for bank loans that could not be repaid as originally contracted with collateral features that enticed creditors to hold these bonds. Since the mid-1990s, most emerging countries have been able to tap international capital markets directly by issuing sovereign bonds. For analytical purposes, the trade-off is that Brady bonds have a longer history, although they only cover countries that experienced debt problems in the 1980s and tend not to represent the marginal cost of new foreign borrowing.

${ }^{8}$ Corporate bonds in advanced economies correspond to BBB investment grade, although similar patterns of behavior were also evident in higher rated bonds. Below-investment grade corporate issues (e.g., BB mortgage-backed securities in the United States) suffered even bigger jumps in their spreads and in volatility. However, because of limitations on the availability of consistent data for below-investment grade bond issues, the data sample in this study is limited to investment grade in advanced economies.
} 
countries. ${ }^{9}$ This introduces some potential difficulties in that the calculated changes will not always be for exactly one day. This is not so much a concern in the model described in Section IV, because the latent factor itself will capture these features, but may disrupt the modeling of the GARCH characteristics. This problem is not perceived as crucial and dealing with it is a topic for future research.

The descriptive statistics of the data suggest, not surprisingly, that developing makets exhibit the greatest spreads between the bond rate and the appropriate 'risk free' rate. ${ }^{10}$ The changes in premiums (Table II.2) paint a similar picture to the levels. The extremes of the changes are larger for the developing markets than the industrial countries. Each of the series in levels fails to reject the null hypothesis of a unit root using the Augmented Dickey Fuller and Phillips Perron tests (Table II.3 in Appendix II). There is also evidence that the series are cointegrated in levels, so that there are common factors in the evolution of the premium series (Table II.4 in Appendix II). In particular, the results show that there are 8 cointegrating equations amongst the 12 premia. These features of the data are encapsulated in the latent factor model specified below.

Tables II.1 and II. 2 show that the degree of kurtosis is generally higher in emerging markets than in the industrial countries. Not unexpectedly, given the nature of financial data in general, each of the series rejects normality in both levels and changes. To that end, various forms of $\mathrm{GARCH}(\mathrm{p}, \mathrm{q})$ models have been fitted to financial returns by a number of authors (e.g., Bollerslev, Chou and Kroner (1992)). The most popular of these models is the $\operatorname{GARCH}(1,1)$. In line with the cointegration results discussed above, an appropriate form to investigate here is given by the model described in (1). Table 1 presents the results estimating this model for each of the premium series (in changes). The changes are examined in order to highlight the properties of the short-term adjustment process in the data.

$$
\begin{aligned}
& \Delta P_{i, t}=\rho_{0}+e_{i, t} \\
& e_{i, t}=\sqrt{h_{i, t}} u_{i, t} \\
& h_{i, t}=\alpha_{0}+\alpha_{1} e_{i, t-1}^{2}+\beta_{1} h_{i, t-1} \\
& u_{i, t} \sim N(0,1),
\end{aligned}
$$

where $\Delta P_{i, t}$ is the change in the premium for country $i$ recorded at time $t$.

\footnotetext{
${ }^{9}$ The data used in this paper is based on contemporaneous date observations for all countries.

${ }^{10}$ Descriptive statistics, unit root and cointegration tests are reported in Appendix II. The descriptive statistics of the premiums (in levels) are summarized in Table II.1 in Appendix II.
} 
An examination of the results in Table 1 reveals that there are some commonalities in the GARCH structure across the series, particularly for the Eastern European and Latin American regions. Indonesia tends to be somewhat different from the other countries in the Asian region.

The data characteristics can be summarized as follows. Each of the premium series exhibits unit root properties, and there is evidence of common factors amongst the premia as highlighted by the result of the cointegration tests. We find that both larger means and absolute movements occur in the premiums in developing markets than the industrialized countries. The data display non-normality, and fitting a univariate $\mathrm{GARCH}(1,1)$ model to the changes in the premiums suggests that there is both a GARCH process in the series, and some evidence of common GARCH characteristics within regions, although this is not necessarily the case for the industrial countries. The common factor and regional characteristics are exploited in the model described in the following section.

Table 1: Univariate GARCH $(1,1)$ Parameter Estimates (QMLE standard errors in brackets)

\begin{tabular}{|c|c|c|c|c|c|}
\hline \multirow[t]{2}{*}{ Country } & \multicolumn{5}{|c|}{ Parameter } \\
\hline & $\rho_{0}$ & $\alpha_{0}$ & $\alpha_{1}$ & $\beta_{1}$ & $\ln \mathrm{L}$ \\
\hline \multicolumn{6}{|l|}{ Industrials } \\
\hline USA & $\begin{array}{c}0.066 \\
(0.100)\end{array}$ & $\begin{array}{c}0.278 \\
(0.511)\end{array}$ & $\begin{array}{c}0.823 \\
(0.655)\end{array}$ & $\begin{array}{c}0.533 \\
(0.260)\end{array}$ & -464.955 \\
\hline U.K. & $\begin{array}{c}0.064 \\
(0.210)\end{array}$ & $\begin{array}{c}1.679 \\
(0.949)\end{array}$ & $\begin{array}{c}0.388 \\
(0.256)\end{array}$ & $\begin{array}{c}0.594 \\
(0.108)\end{array}$ & -553.943 \\
\hline Netherlands & $\begin{array}{c}0.024 \\
(0.341)\end{array}$ & $\begin{array}{c}2.471 \\
(1.674)\end{array}$ & $\begin{array}{c}0.143 \\
(0.103)\end{array}$ & $\begin{array}{c}0.786 \\
(0.098)\end{array}$ & -635.544 \\
\hline \multicolumn{6}{|l|}{ East. Europe } \\
\hline Russia & $\begin{array}{l}-4.390 \\
(4.922)\end{array}$ & $\begin{array}{c}0.507 \\
(8.068)\end{array}$ & $\begin{array}{c}0.461 \\
(0.214)\end{array}$ & $\begin{array}{c}0.849 \\
(0.055)\end{array}$ & -1342.72 \\
\hline Poland & $\begin{array}{l}-0.205 \\
(0.933)\end{array}$ & $\begin{array}{c}23.252 \\
(26.971)\end{array}$ & $\begin{array}{c}0.322 \\
(0.303)\end{array}$ & $\begin{array}{c}0.675 \\
(0.253)\end{array}$ & -896.908 \\
\hline Bulgaria & $\begin{array}{c}0.061 \\
(1.727)\end{array}$ & $\begin{array}{c}51.849 \\
(35.352)\end{array}$ & $\begin{array}{c}0.404 \\
(0.153)\end{array}$ & $\begin{array}{c}0.665 \\
(0.087)\end{array}$ & -1087.07 \\
\hline \multicolumn{6}{|l|}{ Asia } \\
\hline Indonesia & $\begin{array}{l}-0.640 \\
(2.320)\end{array}$ & $\begin{array}{c}255.557 \\
(193.374)\end{array}$ & $\begin{array}{c}0.887 \\
(0.609)\end{array}$ & $\begin{array}{c}0.483 \\
(0.145)\end{array}$ & $-1,084.98$ \\
\hline S. Korea & $\begin{array}{c}-0.498 \\
(1.141)\end{array}$ & $\begin{array}{c}17.207 \\
(10.783)\end{array}$ & $\begin{array}{c}0.244 \\
(0.131)\end{array}$ & $\begin{array}{c}0.794 \\
(0.052)\end{array}$ & -946.888 \\
\hline Thailand & $\begin{array}{l}-0.592 \\
(1.053)\end{array}$ & $\begin{array}{c}30.053 \\
(28.997)\end{array}$ & $\begin{array}{c}0.183 \\
(0.183)\end{array}$ & $\begin{array}{c}0.780 \\
(0.153)\end{array}$ & -906.408 \\
\hline \multicolumn{6}{|c|}{ Lat. America } \\
\hline Mexico & $\begin{array}{c}0.057 \\
(0.707)\end{array}$ & $\begin{array}{c}9.985 \\
(6.628)\end{array}$ & $\begin{array}{c}0.408 \\
(0.153)\end{array}$ & $\begin{array}{c}0.651 \\
(0.093)\end{array}$ & -853.656 \\
\hline Argentina & $\begin{array}{c}0.351 \\
(0.865)\end{array}$ & $\begin{array}{l}9.958 \\
(6.779)\end{array}$ & $\begin{array}{c}0.377 \\
(0.117)\end{array}$ & $\begin{array}{c}0.691 \\
(0.067)\end{array}$ & -915.111 \\
\hline Brazil & $\begin{array}{c}0.759 \\
(1.688)\end{array}$ & $\begin{array}{c}21.946 \\
(19.946)\end{array}$ & $\begin{array}{c}0.311 \\
(0.097)\end{array}$ & $\begin{array}{c}0.745 \\
(0.059)\end{array}$ & $-1,022.350$ \\
\hline
\end{tabular}




\section{A Factor Model OF THE "Premium"}

Volatility in the premiums of each country are hypothesized to be influenced by events that are country specific and events that are common to all economies. However, it is difficult to ascertain what these events may be. In the existing literature, contagion is tested conditioned on controlling for particular events which have been chosen by the researcher after the observed financial crises (see, for example, the selections of indicators in Eichengreen et al (1995, 1996), Sachs, Tornell and Velasco (1996), Glick and Rose (1999)). The economic indicators chosen in this way are often statistically insignificant, and it is difficult to know whether they are the 'correct' choice even ex-post. A more desirable alternative, noted by other authors such as Dooley (2000) and Edwards (2000), is to use a modelling specification which does not require the choice of specific indicators with which to associate the crises, that is to use latent factors.

Latent factor models have been specified for a number of markets. The majority of empirical work has occurred in currency and equity markets (Diebold and Nerlove (1989), Ng, Engle and Rothschild (1992), Mahieu and Schotman (1994), King, Sentana and Wadhwani (1995), Dungey (1999)). The empirical work in interest rates is rather less extensive, but includes Gregory and Watts (1995) and Dungey, Martin and Pagan (2000), the former of which applies to long bond yields and the latter to spreads between individual country bonds and the U.S. bond.

The model to be specified here has more in common with those proposed for the equity markets (e.g., Forbes and Rigobon (1999)). Although these models have been set forth, they are generally not estimated due to identification problems. Specifically, it is difficult to identify the common factor. Here, the identification problem is solved using indirect estimation techniques.

The basic model, similar to that in Forbes and Rigobon (1999) and King, Sentana and Wadhini (1995) can be expressed as follows:

$$
P_{i, t}=\lambda_{i} W_{t}+\phi_{i} f_{i, t} \quad i=1 \ldots n,
$$

where $P_{i, t}$ is the premium on the bond in country $i$ at time $t$. It is the sum of a time-varying common factor $W_{t}$ and a time-varying country-specific factor $f_{i, t}$. The loadings on these factors are given by the parameters $\lambda_{i}$ and $\phi_{i}$ respectively. The common factor $W_{t}$ affects the premiums in all countries, but with a differing parameter in each case. In this form, the addition of an identification condition on the variance covariance matrix allows the model to be estimated by either the Kalman filter or the Generalized Method of Moments (GMM). Dungey (1999) assumes the covariance matrix of the latent factors to be an identity matrix and estimates with GMM on the second moments. Under a similar assumption this model could be estimated with data for at least 3 countries, that is $n \geq 3$ is a necessary identification condition. 
In the current application, we specifically wish to incorporate potential regional effects in the data. In earlier work regional effects have played an important role in the empirical results; Kose, Otrok and Whiteman (1999) use regional influences on macroeconomic data; Dungey, Fry and Martin (2001) model the impact of the 'Asia region' on other currencies during the 1997-98 East Asian currency crisis. To incorporate these regional effects, equation (2) is modified as follows:

$$
P_{i, t}=\lambda_{i} W_{t}+\phi_{i} f_{i, t}+\gamma_{\mathrm{i}} \mathrm{R}_{\mathrm{k}, \mathrm{t}} \quad i=1, \ldots, n, k=1, \ldots, K
$$

where $R_{k, t}$ is a time-varying regional factor. There are $K$ regions, each of which comprises no less than two of the $n$ countries in the model. Hence, the first region for example, may comprise countries $i=1,3,5$. A country is restricted to belong to only one region so that the $K$ regions contain at most as many elements as countries, the total number of elements of $K$ may be less than $n$, if some countries do not belong to any particular region. Where there are non-regionalized countries they enter the system with $R_{k, t}=0$ for all $t$, or simply as per equation (2).

Consider the application of this model to our panel of 12 countries, ordered from 1 to 12 as Argentina, Brazil, Mexico, Indonesia, South Korea, Thailand, Russia, Poland, Bulgaria, United States, United Kingdom, and the Netherlands. Three economic regions are specified in the model, implying three regional factors. The first is a regional factor common to the Latin American economies of Argentina, Brazil and Mexico, denoted $\mathrm{R}_{\text {Lat,t. }}$ The second is a regional factor common to the Asian economies of Indonesia, South Korea and Thailand, $\mathrm{R}_{\mathrm{As}, \mathrm{t}}$ whilst the third regional factor of Eastern Europe is common to Bulgaria, Poland and Russia, denoted $\mathrm{R}_{\text {Eur,t. }}$ No regional factor is included for the industrialized region, comprising the United States, the United Kingdom and Netherlands. This implies that the inclusion of the industrialized countries, region 4, is used to provide a more global estimate of the world factor, $W_{t}$. A model of the premium $P_{i, t}$, without contagion is explicitly specified in (4)

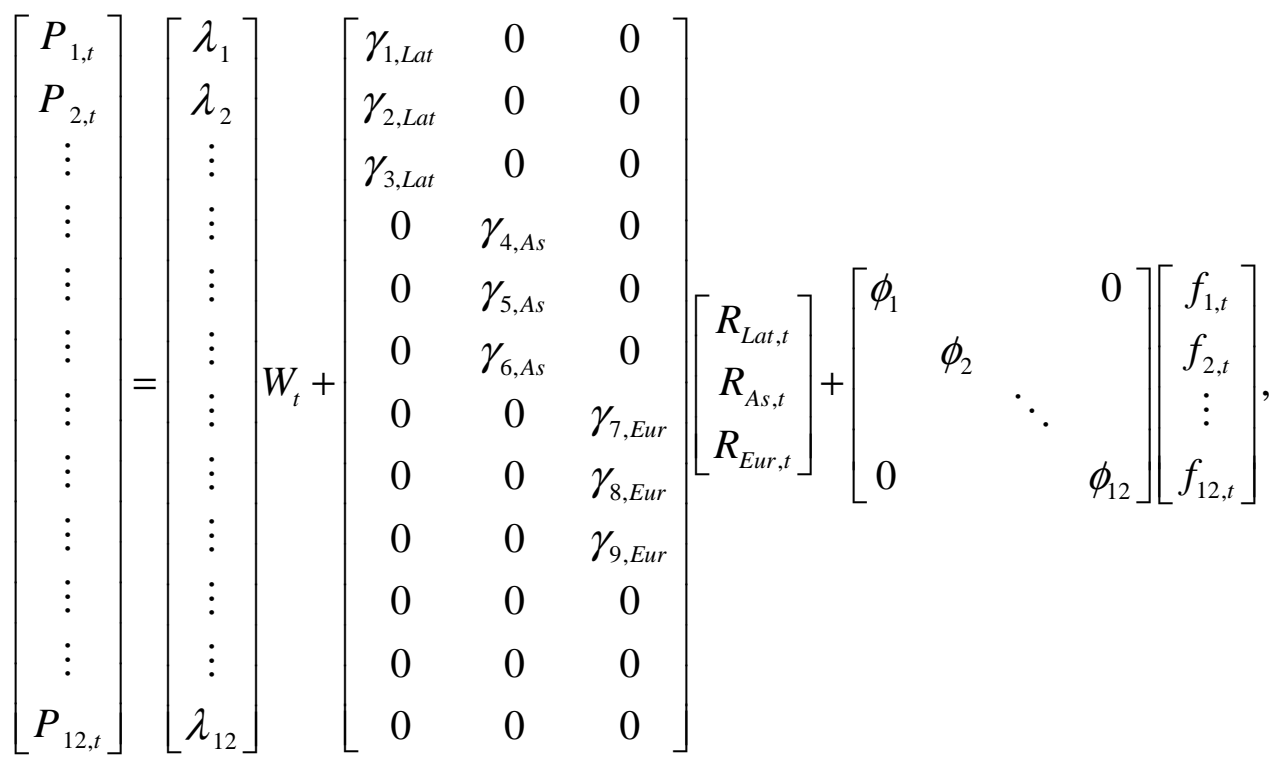


where the three regions are given by Lat (Latin America), As (Asia), and Eur (Eastern Europe). The premium associated with each country can be decomposed into a set of factors. These are a world factor, regional factors, and idiosyncratic factors. The world factor, $W_{t}$, is common to all countries. In line with the unit root properties and cointegration results of the previous section (see Tables 3 and 4 in Appendix II), this process is specified as integrated of order one

$$
W_{t}=W_{t-1}+\eta_{t}
$$

where $\eta_{t}$ is a stationary disturbance term. The regional factors in (4) are also specified as integrated processes of order one

$$
R_{k, t}=R_{k, t-1}+v_{k, t} \text { where } k=\text { Lat, As, Eur, }
$$

where $v_{k, t}$ are stationary disturbance terms. Equation (4) shows that each premium has a unique idiosyncratic error, $f_{i, t}$. If the idiosyncratic error $f_{i, t}$ is stationary, this equation implies that

$$
\left\{\begin{array}{llll}
P_{1, t} & P_{2, t} & \cdots & P_{12, t}
\end{array}\right\}
$$

constitutes a cointegrated system and that (4) represents its common trend representation whereby the world and regional factors are the common trends. To complete the specification of the non-contagion model, the disturbance processes are assumed to be distributed as

$$
\eta_{t}, v_{1, t}, v_{2, t}, v_{3, t}, f_{1, t}, f_{2, t} \ldots f_{12, t} \sim N\left(0, H_{t}\right)
$$

where in general $\mathrm{H}_{\mathrm{t}}$ is a 16-variate system of independent GARCH processes with unit unconditional variances. In the application here we restrict the GARCH to the world factor. ${ }^{11}$

To allow for contagion, the effects of unanticipated shocks from other regions on the premium in country $i$ are incorporated by augmenting (4). In the augmented system shown in equation (9) the parameters $\delta_{i, j}$ represent the effect of an unanticipated shock from country $j$ on country $i$, where the unanticipated shock is given by $f_{j, t}$ in equation (4). The effects of the unanticipated shocks represent the role of contagion in the model. There are no own effects, that is $\delta_{i, j}=0$ when $i=j$.

${ }^{11}$ The three regional factors were also assumed to exhibit GARCH processes, but were found to be statistically insignificant. 
In this application we are interested in the effects of contagion from the Russian shock (as an international credit risk shock) and the LTCM crisis (as an international liquidity shock). The LTCM shock is assumed to be represented by a U.S. based shock. The model given in (9) has this form, but could easily be extended to include a wider range of shocks. ${ }^{12}$

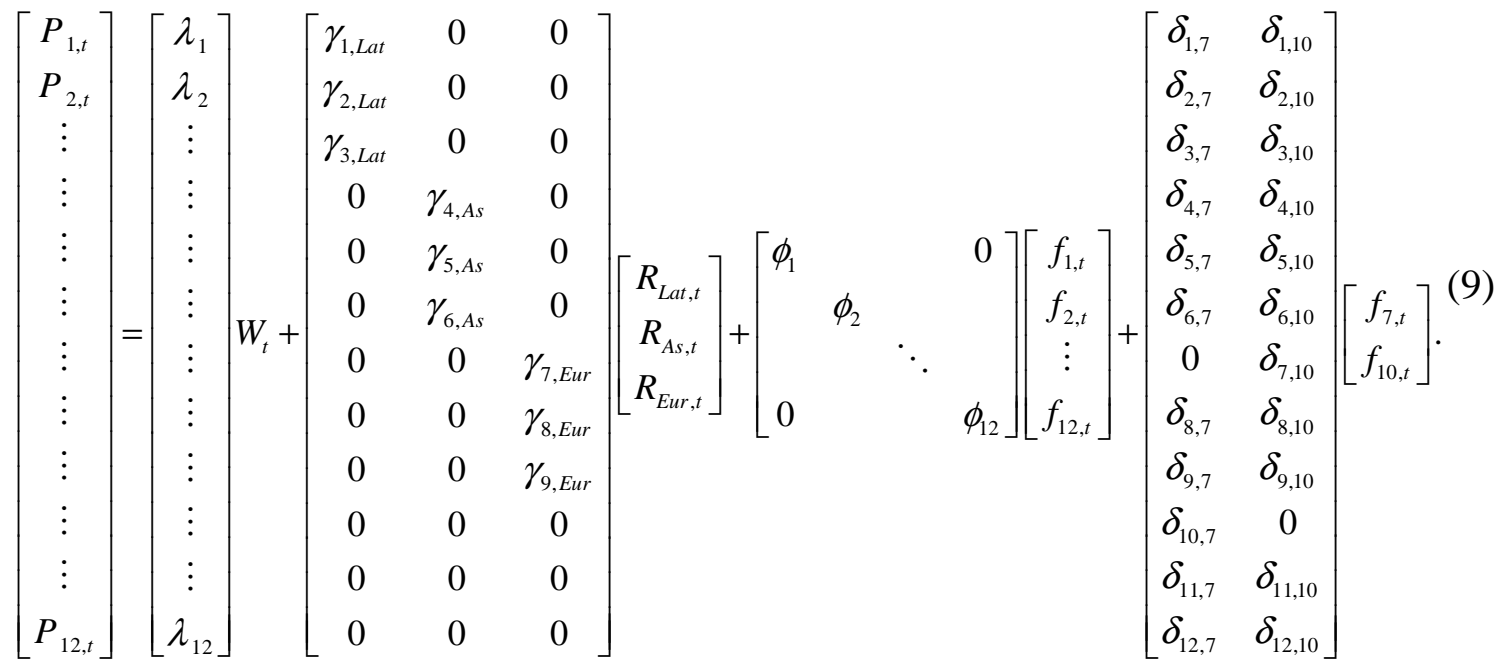

Given that (4) constitutes a cointegrated system, contagion has the effect of causing the risk premia to deviate from its long-run path. As the unanticipated spillover shocks $f_{j, t}$, are stationary, the effect of contagion is temporary.

${ }^{12}$ In an earlier version we examined the effects of regional shocks, in which case (9) is amended to be as follows:

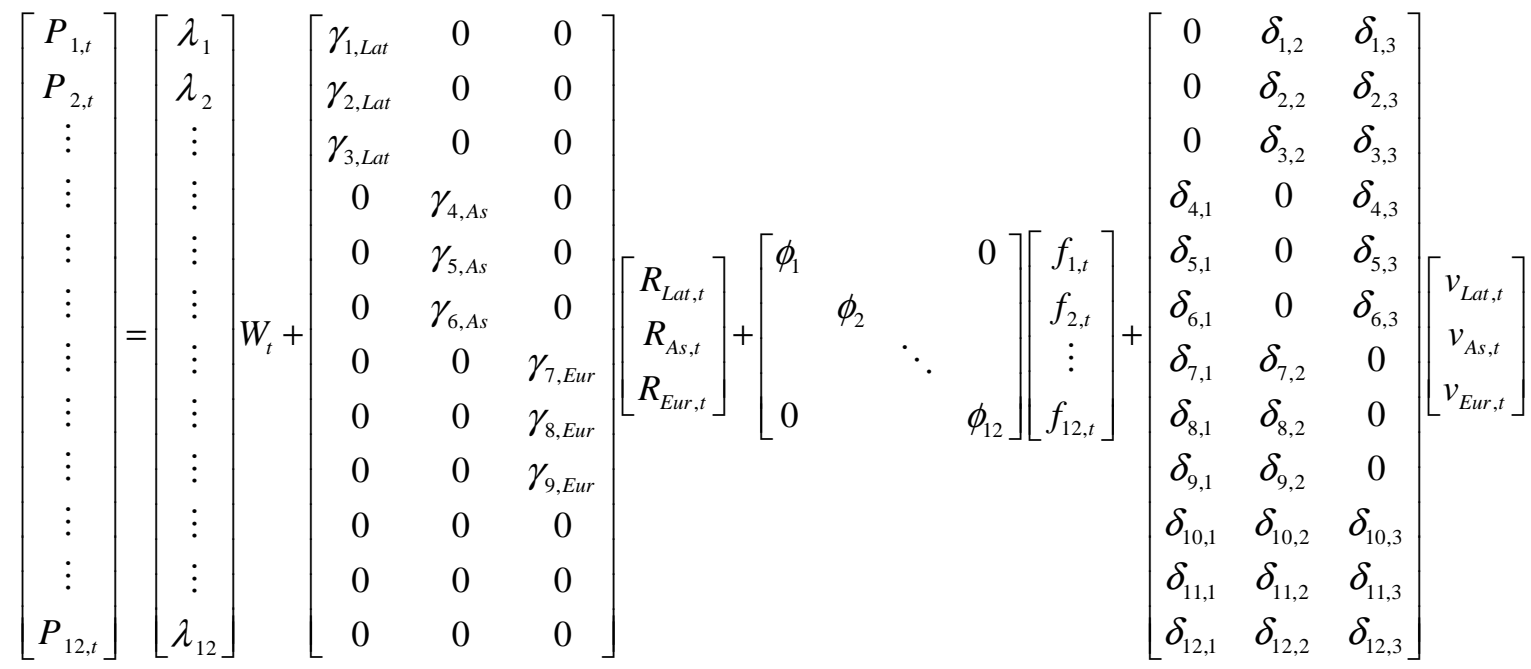


A useful way of examining the results from estimating a model such as (9) is to consider the contribution each factor makes to total volatility in the series. The non-stationary nature of the data in levels means that an unconditional variance decomposition of the model specified in (9) would be undefined. An appropriate solution is to derive volatility decompositions from the error correction representation of equation (9). As a result we compute the variance decomposition in terms of the changes in the premiums, a notion akin to returns in other series. The error correction representation of the ith premium is given by:

$$
\begin{aligned}
& \Delta P_{i, t}=-\left(P_{i, t-1}-\lambda_{i} W_{t-1}-\gamma_{i} R_{k, t-1}\right)+\lambda_{i} \Delta W_{t}+\gamma_{i} \Delta R_{k, t}+\delta_{i, 7} f_{7, t}+\delta_{i, 10} f_{10, t}+\phi_{i} f_{i, t} \\
& \text { or } \\
& \Delta P_{i, t}=-u_{i, t-1}+\lambda_{i} \Delta W_{t}+\gamma_{i} \Delta R_{k, t}+\delta_{i, 7} f_{7, t}+\delta_{i, 10} f_{10, t}+\phi_{i} f_{i, t}
\end{aligned}
$$

where

$$
u_{i, t-1}=P_{i, t-1}-\lambda_{i} W_{t-1}-\gamma_{i} R_{k, t-1},
$$

is the error-correction term. The unconditional volatility decomposition of equation (11) is

$$
\operatorname{Var}\left(\Delta P_{i, t}\right)=\operatorname{Var}\left(u_{i, t-1}\right)+\lambda_{i}^{2}+\gamma_{i}^{2}+\delta_{i, 7}^{2}+\delta_{i, 10}^{2}+\phi_{i}^{2},
$$

which is based on the property that the processes are all independent with unit unconditional variances (see Diebold and Nerlove (1989)). Now the error-correction term can be rewritten by using equation (12)

$$
u_{i, t-1}=\delta_{i, 7} f_{7, t-1}+\delta_{i, 10} f_{10, t-1}+\phi_{i} f_{i, t-1},
$$

which implies that

$$
\operatorname{Var}\left(u_{i, t-1}\right)=\delta_{i, 7}^{2}+\delta_{i, 10}^{2}+\phi_{i}^{2}
$$

Using equations (13) and (15) the total variance in the premiums for each economy can be decomposed into proportions due to each of the factors. Hence, in Section V we present results on the percentage contribution to total volatility for the common world factor, $W_{t}$, the regional factor (for the non-industrial countries), $R_{k, t}$, the country-specific factor, $f_{i, t}$ and contagion from the United States and Russia. Some part of the contagion and countryspecific factor comes from the relationship in (13) and a further component from the decomposition in equation (15). To see this, (13) and (15) can be combined to express total volatility,

$$
\operatorname{Var}\left(\Delta P_{i, t}\right)=\lambda_{i}^{2}+\gamma_{i}^{2}+2 \sum_{l=1}^{2} \delta_{i, l}^{2}+2 \phi_{i}^{2}
$$


The results of interest are then given as the proportion of total volatility in the changes in the premium for country $i$ due to the:

(i) contribution of the world factor

(ii) contribution of the regional factor

(iii) contribution of country-specific factor

(iv) contribution of contagion from Russia

(v) contribution of contagion from the United States
$\frac{\lambda_{i}^{2}}{\operatorname{Var}\left(\Delta P_{i}\right)}$
$\frac{\gamma_{i}^{2}}{\operatorname{Var}\left(\Delta P_{i}\right)}$

$\frac{2 \phi_{i}^{2}}{\operatorname{Var}\left(\Delta P_{i}\right)}$

$\frac{2 \delta_{i, 7}^{2}}{\operatorname{Var}\left(\Delta P_{i}\right)}$

$\frac{2 \delta_{i, 10}^{2}}{\operatorname{Var}\left(\Delta P_{i}\right)}$

\section{RELATIONSHIP WITH EXISTING LITERATURE}

The models estimated in this paper decompose volatility in the spread between long bonds and the appropriate 'risk free' rate, or the premium, for a variety of economies into a set of latent factors, whilst controlling for the long-run relationships of the model though the estimation of a cointegrating system. The factors are a world factor which captures information in the system common to all economies, a set of regional factors which captures information in the system specific to a group of the less developed economies according to geographical location, and unanticipated idiosyncratic factors which are unique to each economy. In addition to these common factors, the effects of unanticipated idiosyncratic shocks originating in the United States and/or Russia which transmit across national borders also account for some proportion of total volatility in spreads. In common with a substantial portion of the literature, this effect is denoted contagion. The contagion factors account for the transmission of unanticipated shocks across countries, after controlling for world events and regional events.

The concept of contagion from both a theoretical and empirical viewpoint is controversial in the literature. The hypothesis of contagion has been explored in applications to various financial and asset markets, with quite distinct streams of literature, although there does not seem to be a particular reason as to why this is the case. ${ }^{13}$ Dornbusch, Park and Claessens (2000) provide a recent overview of the issues. The definition of contagion adopted in this paper is that contagion reflects the spillover effect of unanticipated

${ }^{13}$ See Dungey and Martin (2001) for an exploration of the linkages between various financial markets, along with a discussion of the development of the literature in each market. 
contemporaneous shocks across countries. This is similar to concepts expressed in Favero and Giavazzi (2000) and Forbes and Rigobon (1999, 2000). In contrast, studies such as Eichengreen, Rose and Wyplosz (1996) and Reside and Gochoco-Bautista (1999) base their view of contagion on the spillover effect of anticipated shocks across countries.

Contagion viewed as unanticipated, or as a residual, is a common theme in the literature (see, for example, Sachs, Tornell and Velasco (1996), Masson (1999a,b,c)). Masson decomposes exchange rate changes into three components. These are "monsoonal shocks", or global shocks affecting all countries simultaneously, equivalent to $W_{t}$ in (9); spillovers, which occur through normal trade and economic relationships, and a residual, which is the component unexplained by these systematic relationships. It is this concept that has been transferred to the empirical applications in Dungey and Martin $(2000,2001)$ and also in this paper.

Masson (1999a,b,c) attributes part of the residual process to multiple equilibria, or sunspots, where there is a role for self-fulfilling expectations leading to contagion if opinions are coordinated across countries (see also Loisel and Martin (2001)). Multiple equilibria models are also consistent with other channels for contagion, such as wake-up calls (e.g., Goldstein (1998)) or heightened awareness (e.g., Lowell, Neu and Tong (1998)). In these cases a reappraisal of one country's fundamentals leads to a reappraisal of fundamentals in other countries, thereby resulting in the transmission of crises. Kyle and Xiong (2001) explain contagion in the LTCM and Russian crises as a wealth effect, as traders trading in risky markets encounter unanticipated shocks and liquidate across their portfolios. Thus, a shock in one market can reverberate in seemingly unconnected markets. Both the wake up call, wealth effect model and Masson's definition of contagion are consistent with the model presented in Section III as long as there is no anticipation of the event.

The transmission of expectations in both the multiple equilibrium and wake up call models can lead to herd behavior (see Kaminsky and Schmukler (1999) and Calvo and Mendoza (2000)). This may be more likely in increasingly integrated international financial markets (International Monetary Fund (1999)). Kruger, Osakwe and Page (1998) consider that herd behavior leads to a concept they distinguish as unwarranted contagion, which occurs when a crisis spreads to another country that otherwise would not have experienced a speculative attack. This is consistent both with contagion as a residual (Masson (1999a,b,c)), and the definition used in this paper. A further potential channel of contagion is through asset bubbles created by moral hazard, or implied or explicit government guarantees. These bubbles may burst through herd behavior (see Krugman (1998)). If this is unanticipated, then crises may again be self-fulfilling, and contagion occurs.

Other views of contagion consistent with the definition adopted in this paper include Favero and Giavazzi (2000) where contagion is a change in the way shocks are transmitted across countries, and Forbes and Rigobon (2000) where there is an increase in cross-market correlations after a shock in one country. The effect of unscheduled, and hence unanticipated country-specific news or announcements also has implications for other countries, and hence is consistent with contagion as defined here (Ellis and Lewis (2000)). 
The effect of 'news' in the transmission of crises has also been investigated by Baig and Goldfajn (1998) who view evidence of contagion in increasing correlations among markets following a crisis. Kaminsky and Schmukler (1999) analyze the effects of news, or lack of news in the stock markets. Contagion is defined in their framework as when investors' moods spread across national borders. Their key result is that some of the largest swings in the stock market occurred on days of no news. Neither Baig and Goldfajn (1998) nor Kaminsky and Schmukler (1999) make a distinction between the anticipated or unanticipated nature of news.

Other authors espouse views of contagion which lie outside of the definition adopted in this paper. They view contagion as an anticipated spillover. In the framework of the model of Section III, this would be captured in the long run relationships of the model. Reside and Gochoco-Bautista (1999) define contagion as the spillover effects of domestic disturbances on nearby or related economies, using lagged changes in the exchange rates as their contagion variable, while Goldstein, Kaminsky and Reinhart (2000) construct a contagion vulnerability index based on correlations between stock markets, trade linkages, presence of common markets and inter-linkages between banking systems. Van Rijckeghem and Weder (2001) construct a subjective binary variable to examine contagion effects due to financial and trade linkages. Eichengreen, Rose and Wyplosz (1996), Wirjanto (1999), and Kruger, Osakwe and Page (1998) condition their models on the existence of a crisis elsewhere, which implies that volatility is anticipated. This aspect fits their definition into either the regional factor or long run relationships of our model.

The factor model developed in Section III is able to encompass many of the existing definitions of contagion in the literature. In particular it brings a focus on the importance of two aspects of contagion, that it be unanticipated and transmitted across borders. The next Section briefly exposits the estimation methodology and Section VI presents estimates of the extent of contagion in the twelve countries described in Section II.

\section{ESTIMATION METHOD}

In the presence of GARCH errors, maximum likelihood methods of estimation such as the Kalman filter, or GMM, do not produce consistent parameter estimates (Gourieroux and Monfort (1994)). As an alternative, we adopt indirect estimation techniques to estimate the models specified in the previous section. Indirect estimation belongs to a class of techniques which match the characteristics of the sample data with those of data simulated from the hypothesized model to obtain the parameter estimates. The key to this technique is that while the model is analytically complex to integrate, it is relatively straightforward to simulate. Other forms of this technique are known as Simulated Method of Moments (SMM) and Efficient Method of Moments (EMM). SMM is associated with the work of Duffie and Singleton (1993), EMM with Gallant and Tauchen (1996) and Indirect Inference with Gourieroux, Monfort and Renault (1993) and Gourieroux and Monfort (1994). The differences between the three methods lie in the way in which the matching proceeds. 
Consider a set of sample data and a model such as specified in equation (9) above. Ideally, we would like to form parameter estimates based on the likelihood of the objective function. However, this is unwieldy. As an alternative, we consider a number of characteristics of the data which capture the salient features of the likelihood - these features are known as the auxiliary model. The choice of auxiliary model is due to the researcher, and appropriate selection is crucial to an efficient outcome. However, its characterization also determines the subclass of estimation technique in use. SMM chooses moment-based characteristics, EMM is based on the scores of the functions and Indirect Inference uses parameter estimates from the specified auxiliary model. In many cases these characterizations are the same; for example, the auxiliary model in Dungey, Martin and Pagan (2000) satisfies each of these criteria.

The optimization process is carried out by minimizing the distance between the characteristics of the auxiliary model from the sample data and the average characteristics of the auxiliary model from the simulated data, where the data is simulated a total of $\mathrm{H}$ times. That is, where $\bar{g}$ represents the auxiliary from the sample data, and $\bar{v}_{h}$ the auxiliary from simulation $h$ of $H$ simulation paths. The indirect estimator, $\hat{\theta}$, is the solution of:

$$
\hat{\theta}=\underset{\theta}{\arg \min }\left[\bar{g}-\frac{1}{H} \sum_{h=1}^{H} \bar{v}_{h}\right]^{\prime} \Omega^{-1}\left[\bar{g}-\frac{1}{H} \sum_{h=1}^{H} \bar{v}_{h}\right],
$$

where $\Omega$ is the weighting matrix computed as follows (see Gourieroux, Monfort and Renault (1993)) with Newey-West weights

$$
\begin{aligned}
& \qquad \Omega=\frac{1}{T} g_{t}^{\prime} g_{t}+\frac{1}{T} \sum_{l}^{L} \omega_{l}\left(g_{t}^{\prime} g_{t-l}+g_{t-l}^{\prime} g_{t}\right) \\
& \text { with } \omega_{l}=1-\frac{1}{L+1} .
\end{aligned}
$$

The auxiliary model used to estimate the system given in (9) including contagion is specified as follows. The first set of conditions is based on a VAR(1) which summarizes the key dynamics of a cointegrating and error correction system. $k^{0}$ in (20) is the product of the residuals taken from a VAR(1) of the levels of the premiums and the lagged values of all premiums in the model, $P_{t-1}$. That is, $k^{0}$ is described by:

$$
k_{t}^{0}=\left\{u_{1 t} P_{t-1}^{\prime}, u_{2 t} P_{t-1}^{\prime}, u_{3 t} P_{t-1}^{\prime}, \ldots u_{12 t} P_{t-1}^{\prime}\right\}
$$

The dimension of $k^{0}$ is $\left(\mathrm{T}^{*} 144\right)$.

The second set of moment conditions corresponds to the variance of the level of the premiums. Formally,

$$
k_{t}^{1}=P_{i, t}^{2}, \quad i \geq 1,2, \ldots, 12 .
$$


Taking the sample mean of $k^{1}$ yields a total of 12 moment conditions.

The third set of moment conditions captures the AR(1) structure of the changes in the premiums. This set contains 12 elements and is specified as:

$$
k_{t}^{2}=\left(\Delta P_{i, t}-\Delta \bar{P}_{i, t}\right)\left(\Delta P_{i, t-1}-\Delta \bar{P}_{i, t-1}\right)
$$

Taking the sample mean of $k^{2}$ yields a total of 12 moment conditions.

The fourth and fifth set of moment conditions are included to capture conditional volatility in the premiums, and are included to capture the GARCH characteristics of the data. It comprises $\mathrm{AR}(1)$ and $\mathrm{AR}(2)$ loadings for the squared changes in the premiums. In a similar manner to Diebold and Nerlove (1989), the number of overidentifying conditions is controlled by including only the 'own' squared autocorrelations of the change in the premium. The corresponding vectors of conditions for the auxiliary model contain a total of 12 elements each

$$
\begin{aligned}
& k_{t}^{3}=\left(\Delta P_{i, t}^{2}-\Delta \bar{P}_{i, t}^{2}\right)\left(\Delta P_{i, t-1}^{2}-\Delta \bar{P}_{i, t-1}^{2}\right) \\
& k_{t}^{4}=\left(\Delta P_{i, t}^{2}-\Delta \bar{P}_{i, t}^{2}\right)\left(\Delta P_{i, t-2}^{2}-\Delta \bar{P}_{i, t-2}^{2}\right) .
\end{aligned}
$$

Taking the sample means of $k^{3}$ and $k^{4}$ yields a further 24 moment conditions.

Collecting all $(144+12+12+12+12)$ time series from $(20)$ to $(24)$ into the $\left(\mathrm{T}^{*} 192\right)$ matrix

$$
g_{t}=\left\{k_{t}^{0}, k_{t}^{1}, k_{t}^{2}, k_{t}^{3}, k_{t}^{4}\right\},
$$

and taking the moment conditions into a matrix yields 192 moment conditions. Taking the mean of $g_{t}$ yields $\bar{g}_{t}$ which is used in the indirect estimator in (17). This matrix summarizes the time series characteristics of the premiums. The simulated matrix $v_{h}$ is similarly constructed as,

$$
v_{h}=\left\{k_{h}^{0}, k_{h}^{1}, k_{h}^{2}, k_{h}^{3}, k_{h}^{4}\right\},
$$

where $k_{h}^{0}, k_{h}^{1}, k_{h}^{2}, k_{h}^{3}$ and $k_{h}^{4}$ are the analogs of equations (20) to (24) for the $h^{\text {th }}$ simulation of the changes in premium, $\widetilde{P}_{i, h}$. The mean of this vector yields $\bar{v}_{h}$ which is used in the indirect estimator given in (17). In constructing the weighting matrix in equation (18) the blocks are assumed to be independent.

To highlight the estimation procedure, consider the following trivariate factor model which contains a world factor, $W_{t}$, and the country-specific factors $f_{i, t}$,

$$
\begin{aligned}
& P_{1, t}=\lambda_{1} W_{t}+\phi_{1} f_{1, t} \\
& P_{2, t}=\lambda_{2} W_{t}+\phi_{2} f_{2, t} \\
& P_{3, t}=\lambda_{3} W_{t}+\phi_{3} f_{3, t},
\end{aligned}
$$


where all four factors are specified as $\mathrm{N}(0,1)$ processes. The number of unknown parameters is 6 ,

$$
\left\{\lambda_{1}, \lambda_{2}, \lambda_{3}, \phi_{1}, \phi_{2}, \phi_{3}\right\}
$$

An appropriate auxiliary model is to choose

$$
g_{t}=\left\{P_{1, t}^{2}, P_{2, t}^{2}, P_{3, t}^{2}, P_{1, t} P_{2, t}, P_{1, t} P_{3, t}, P_{2, t} P_{3, t}\right\} .
$$

Taking the sample mean gives

$$
\bar{g}=\left\{s_{1}^{2}, s_{2}^{2}, s_{3}^{2}, s_{12}, s_{13}, s_{23}\right\},
$$

which represent the unique variances, $s_{j}^{2}$, and covariances, $s_{i j}$, of the data. These sample moments summarize all of the covariance properties of the data.

Now for an initial set of starting values in (30), the factor model in equations (27) to (29) can be simulated to yield simulated time series of the four factors, and in turn, simulated time series of the three premia. This is repeated $H$ times, where $P_{i, h}$, represents the $h^{\text {th }}$ simulated time series of the $i^{\text {th }}$ premium. The set of simulated time series are then used to evaluate the auxiliary model corresponding to (31).

$$
v_{h}=\left\{P_{1, h}^{2}, P_{2, h}^{2}, P_{3, h}^{2}, P_{1, h} P_{2, h}, P_{1, h} P_{3, h}, P_{2, h} P_{3, h}\right\} .
$$

Taking the sample mean yields

$$
\bar{v}_{h}=\left\{s_{1, h}^{2}, s_{2, h}^{2}, s_{3, h}^{2}, s_{12, h}, s_{13, h}, s_{23, h}\right\}
$$

which are the unique variances, $s_{j, h}^{2}$, and covariances, $s_{i j, h}$, of the simulated data corresponding to the $h^{\text {th }}$ simulation. The indirect estimator consists of updating the starting parameter values until

$$
\bar{g}=\frac{1}{H} \sum_{h=1}^{H} \bar{v}_{h},
$$

where the right handside is the sample mean of the $H$ simulated values of the simulated variances and covariances. As the number of moment conditions in the auxiliary model equals the number of unknown parameters, the model is just identified. For overidentified models where the number of moment conditions of the auxiliary model exceeds the number of unknown parameters, a more general objective function is needed as given in (17).

The indirect estimator in equation (17) is solved using the standard gradient algorithms from OPTMUM in GAUSS version 3.2, where gradients are computed numerically. The simulations are based on normal random numbers from the GAUSS procedure RNDN. ${ }^{14}$

${ }^{14}$ All results are for 500 simulation paths with a convergence tolerance of 0.001 . 


\section{EMPIRICAL RESULTS}

The results from the estimation of two models are presented in this section. The first model allows for the transmission of contagion from Russia to the other economies in the sample ${ }^{15}$ whilst the second extends the first model by allowing for contagion from both Russia and the United States (which proxies the LTCM shock) to all other economies. ${ }^{16}$ Reiterating, contagion is said to exist if the unanticipated shocks from Russia, or the United States in the second estimation, spillover to explain a significant proportion of the volatility in the premiums of other countries in the sample. The unanticipated shocks are measured by the country specific (idiosyncratic) factor for Russia or the United States in the premium equations of other countries.

Table 2 presents the unconditional volatility decomposition of the changes of the premiums of each economy from estimation of the base model of contagion emanating only from Russia. The same information is also presented graphically in Figure 5. ${ }^{17}$ Total volatility is decomposed into the contribution due to the world factor, regional factors, country-specific or idiosyncratic factors and contagion from Russia, using equation (16) in Section III.

In general, the dominant factor in the volatility decomposition of the change in the bond premiums is the world factor, pointing strongly towards commonality in the movements in premiums. This result is consistent with the view that increasing financial market integration have led to high (and expected) co-movements. The world factor accounts for between 82 percent (Netherlands) and 99.9 percent (United Kingdom) of total volatility. A corollary of this is that the regional factors have little influence on volatility, with all accounting for less than one percentage point of total volatility. Country-specific factors are relatively important for the United States, Russia, Argentina and South Korea but in each case account for no more than 15 percent of total volatility. The United States has a relatively large idiosyncratic factor. This is consistent with the possibility that the LTCM crisis shock is missing from this analysis, which is discussed below. Overall, the transmission of contagion

\footnotetext{
${ }^{15}$ An earlier version of this model presents the results of contagion emanating from the Eastern European region to all other economies in the sample. The change to only Russia being the source of contagion made remarkably little difference to the results, pointing to the importance of the Russian premiums in driving the results for this region during the period.

${ }^{16}$ Experiments extending this class of model to allow for contagion from the Latin American and Asian regions in conjunction with contagion from the United States and Russia were undertaken to allow for the most general specification. However, this line of research was not pursued due to an undesirable amount of parameter instability inherent in the larger models.

${ }^{17}$ Figures 5 and 6 have been rescaled to begin at a contribution of $80 \%$ in order to show the smaller components more clearly. The missing lower portion corresponds to the world factor.
} 
from Russia contributes between 0 and 17 percent of total volatility of the changes in the bond spreads.

Table 2: Volatility Decomposition with Contagion Effects from Russia (contribution to total volatility, in percent)

\begin{tabular}{lcccc}
\hline & World & Country & Regional & $\begin{array}{c}\text { Contagion } \\
\text { From } \\
\text { Russia }\end{array}$ \\
\hline Industrial & & & & \\
U.S. & 84.999 & 11.793 & - & 3.208 \\
U.K. & 99.906 & 0.005 & - & 0.090 \\
Netherlands & 82.472 & 0.490 & - & 17.037 \\
Eastern & & & & \\
Europe & & & & \\
Russia & 97.716 & 5.176 & 0.108 & - \\
Poland & 93.636 & 0.063 & 0.657 & 7.693 \\
Bulgaria & 91.578 & 0.210 & 0.520 & 0.292 \\
Asia & & & & 1.883 \\
Indonesia & 99.244 & 0.260 & 0.204 & 6.714 \\
South Korea & 92.284 & 4.198 & 0.916 & \\
Thailand & 91.910 & 0.989 & 0.387 & \\
Latin & & & & 0.139 \\
America & & & & 16.413 \\
Mexico & 99.852 & 0.001 & 0.007 & \\
Argentina & 86.906 & 12.687 & 0.048 & \\
Brazil & 83.328 & 0.256 & 0.003 & \\
\hline
\end{tabular}

As anticipated, the results of estimation of the base model indicate that contagion from Russia to other countries within the Eastern European block is relatively high. Further, in terms of contribution to percentage volatility, there is little evidence to support the hypothesis that contagion emanating from Russia is confined to developing nations (a view supported by some observers, such as the Bank for International Settlements (1999)). The transmission of contagion is evident not only to countries within Asia and Latin America, but also to the industrial nations in the sample. In particular, substantial amounts of volatility in the premium changes of the Netherlands, Thailand and Brazil are accounted for by contagion from Russia (17 percent, 7 percent and 16 percent, respectively). ${ }^{18}$

18 The Netherlands is geographically close to Russia, which may lend support for the hypothesis common in the literature of the regional nature of contagion; see for example Goldstein (1998), Kaminsky and Reinhart (2000), Goldstein, Kaminsky and Reinhart (2000), Eichengreen, Rose and Wypolz (1996), Glick and Rose (1999) and Masson (1999b). 
It is difficult to derive any stylized facts to either support or refute the contention that developing markets are more affected by contagion than developed markets. Not only is there evidence that contagion affects both developed and developing markets, but other evidence similarly indicates that some developing and developed markets are not affected by contagion. As shown in Table 2, a number of countries are little affected by Russia, with less than one percentage point of total volatility in the United Kingdom, Mexico, Argentina and Indonesia attributed to contagion.

Figure 5: Volatility Decomposition with Contagion effects from Russia (contribution to total volatility, in percent)

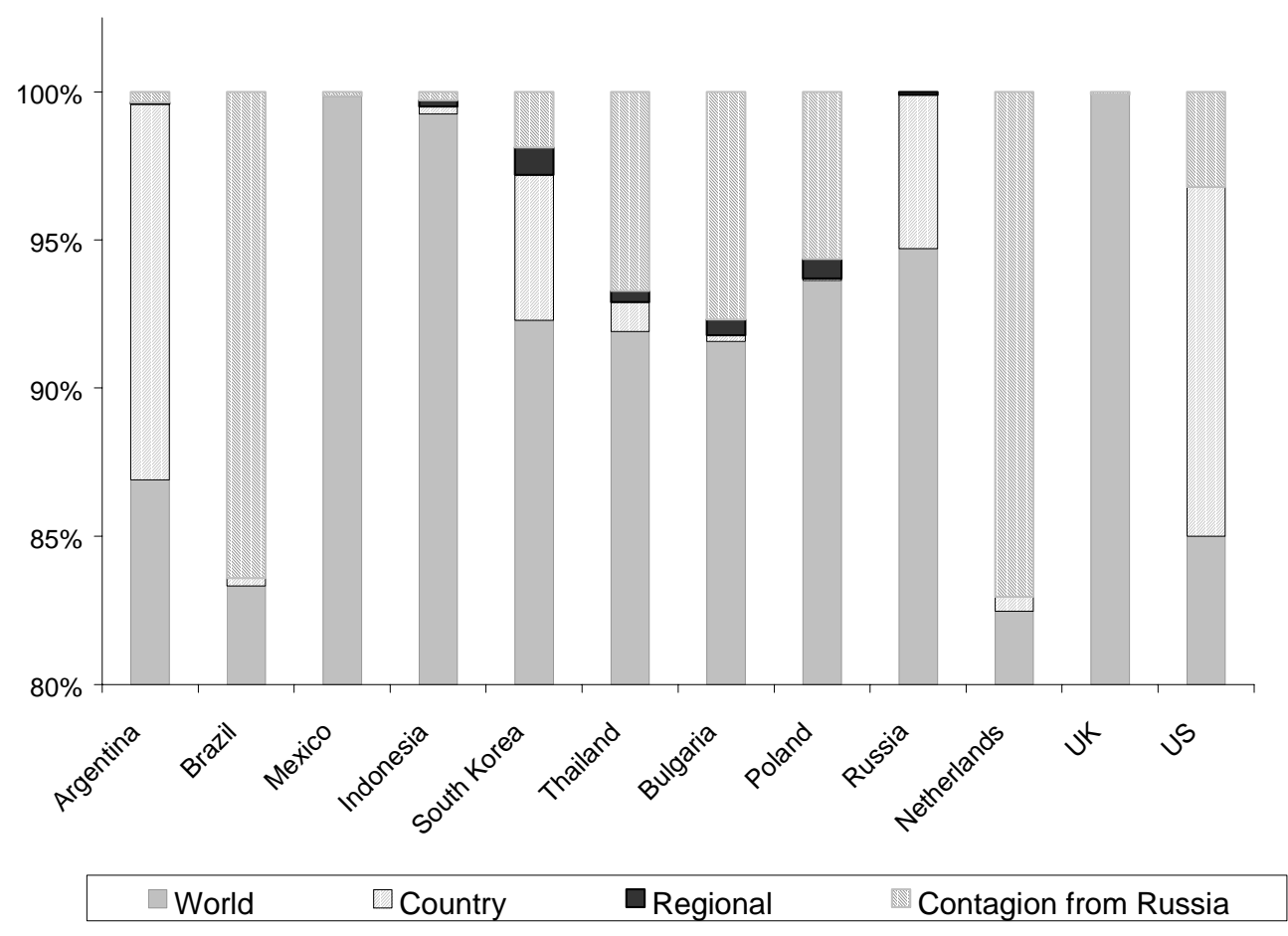

To shed some further light on this issue, the results for each country are scaled by the level of volatility in each market to obtain a measure of the magnitude of contagion in absolute terms, rather than in terms of percentage contribution to volatility. The total level of volatility in basis points is given as the square of the standard deviations reported for each country in Table II. 2 in Appendix II. Table 3 presents the decomposition results scaled by the variance of the changes in premium for each country. The components of the bond spreads for each country now sum to the number of basis points comprising the variance of the change in the premium for that country.

Table 2 provided mixed evidence on the question of whether developing countries are more affected by contagion than developed countries, but Table 3 shows that in terms of absolute magnitude of contribution to basis point swings, contagion is generally greater for 
developing countries. For example, although contagion accounts for 17 percent of total volatility in the Netherlands, its contribution in basis points is less than for all of the developing countries in the sample except for Mexico and Argentina. In the Netherlands and Argentina, contagion accounts for similar magnitudes (around 4 basis points) even though the percentage contribution of contagion in the Netherlands is 17 percent and less than one percent in Argentina. Further, Table 2 indicates that around 7-8 percent of total volatility in Thailand and Bulgaria is due to contagion. However, in terms of basis point changes, the Bulgarian result is some 25 times that of Thailand.

Table 3: Volatility Decomposition with Contagion Effects from Russia (contribution to total volatility, in basis points)

\section{Total}

\section{Components}

\begin{tabular}{|c|c|c|c|c|c|}
\hline & & World & Country & Regional & Contagion \\
\hline \multicolumn{6}{|l|}{ Industrial } \\
\hline U.S. & 7.503 & 6.381 & 0.885 & - & 0.241 \\
\hline U.K. & 13.913 & 13.900 & 0.001 & - & 0.012 \\
\hline Netherlands & 29.052 & 23.960 & 0.142 & - & 4.950 \\
\hline \multicolumn{6}{|l|}{ Eastern } \\
\hline \multicolumn{6}{|l|}{ Europe } \\
\hline Russia & 58782.003 & 55675.870 & 3042.761 & 63.372 & - \\
\hline Poland & 527.621 & 494.046 & 0.333 & 3.467 & 29.776 \\
\hline Bulgaria & 10006.001 & 9163.274 & 21.014 & 51.994 & 769.719 \\
\hline \multicolumn{6}{|l|}{ Asia } \\
\hline Indonesia & 3121.457 & 3097.846 & 8.130 & 6.356 & 9.125 \\
\hline South Korea & 820.250 & 756.958 & 40.340 & 7.511 & 15.442 \\
\hline Thailand & 499.970 & 459.522 & 4.944 & 1.936 & 33.568 \\
\hline \multicolumn{6}{|l|}{ Latin } \\
\hline \multicolumn{6}{|l|}{ America } \\
\hline Mexico & 526.703 & 525.924 & 0.006 & 0.038 & 0.734 \\
\hline Argentina & 1133.669 & 985.225 & 143.830 & 0.542 & 4.073 \\
\hline Brazil & 3515.304 & 2929.220 & 9.016 & 0.118 & 576.950 \\
\hline
\end{tabular}

Overall, when measuring the transmission of contagion in actual basis points, the results support the hypothesis that developing countries are more affected by contagion than developed markets. This largely reflects the fact that markets in developing countries are more volatile than those in advanced economies. What has been unclear in the literature is the source of that higher volatility. The approach proposed in this paper is able to disentangle how much of the volatility is due to world and country-specific effects, as well as contagion.

As highlighted earlier, one conjecture in the literature is that the Russian crisis and the LTCM crisis in the United States affected emerging and mature markets differently. One interpretation of the international contagion effects resulting from Russia and the LTCM 
near-default is that the first primarily reflects increased credit risk concerns, while the second worked as a global liquidity shock. ${ }^{19}$

To examine the differences between the transmission of the Russian crisis and the LTCM near-collapse, the model is augmented to allow for unanticipated shocks from the United States to impact on the other countries in the sample. This augmentation uses a U.S. based shock to proxy the LTCM near-collapse. The results of this are shown in Table 4 and Figure 6.

Table 4: Volatility Decomposition with Contagion Effects from Russia and the United States (contribution to total volatility, in percent)

\begin{tabular}{lcccccc}
\hline & & & & \multicolumn{3}{c}{ Contagion } \\
\cline { 5 - 7 } & World & Country & Regional & From Russia & From U.S. & Total \\
\cline { 6 - 8 } Industrial & & & & & & \\
U.S. & 91.080 & 0.050 & 0.000 & 8.870 & - & 8.870 \\
U.K. & 99.344 & 0.133 & 0.000 & 0.040 & 0.482 & 0.523 \\
Netherlands & 82.793 & 2.777 & 0.000 & 10.615 & 3.815 & 14.431 \\
Eastern Europe & & & & & & \\
Russia & 89.145 & 0.222 & 0.086 & - & 10.547 & 10.547 \\
Poland & 88.963 & 0.050 & 0.514 & 1.279 & 9.194 & 10.473 \\
Bulgaria & 90.204 & 0.375 & 0.417 & 8.111 & 0.893 & 9.004 \\
Asia & & & & & & \\
Indonesia & 99.213 & 0.268 & 0.254 & 0.217 & 0.048 & 0.265 \\
South Korea & 91.285 & 5.269 & 0.913 & 0.163 & 2.369 & 2.533 \\
Thailand & 91.174 & 0.786 & 0.547 & 1.521 & 5.973 & 7.493 \\
Latin America & & & & & & \\
Mexico & 99.426 & 0.003 & 0.002 & 0.327 & 0.242 & 0.569 \\
Argentina & 83.436 & 0.028 & 0.007 & 0.022 & 16.508 & 16.529 \\
Brazil & 84.388 & 0.055 & 0.045 & 11.1047 & 4.407 & 15.511 \\
\hline
\end{tabular}

19 This interpretation is consistent with the widening of the liquidity premium on otherwise similar assets following the LTCM shock. The credit risk view of the Russian shock is also consistent with a cash-out of liquid markets with increased credit risks as investors' rebalanced their portfolios. 
Figure 6: Volatility Decomposition with Contagion effects from Russia and the United States (contribution to total volatility, in percent)

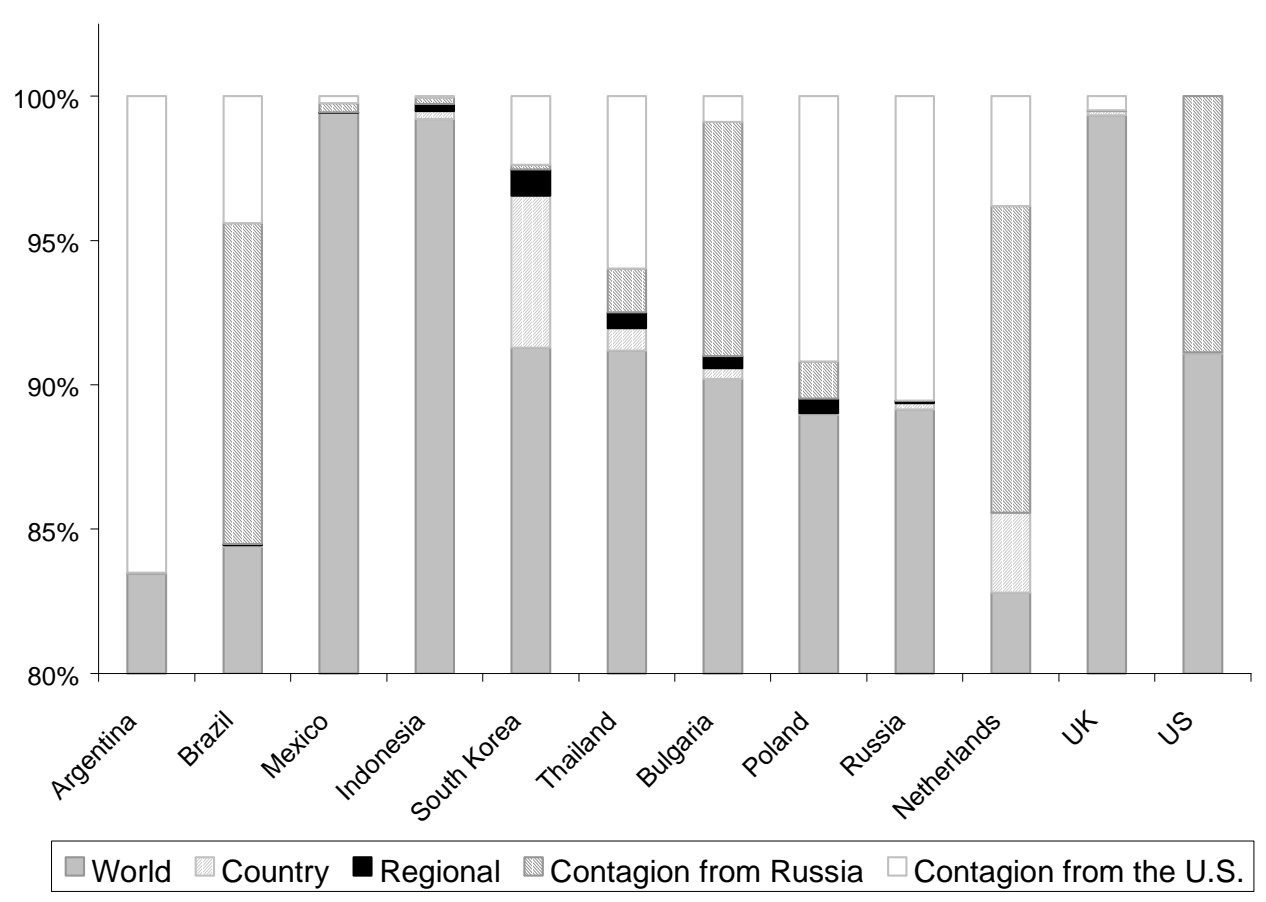

The changes in the volatility decompositions as a result of the inclusion of contagion from the United States can be fairly neatly categorized into two directions. First, is that in most countries there is an increase in the contribution of contagion to total volatility. (This is the sum of contagion emanating from Russia and the U.S.). Second, the redistribution of the factors towards contagion has come primarily from the global factor; that is, most of the increase in the proportion of volatility due to contagion is balanced by a fall in the contribution of the global factor. One interpretation of this is that the inclusion of contagion from the LTCM has correctly identified a factor which had a noticeable impact on most of the markets in the sample. The main exception to this observation is the Netherlands where the contribution of contagion falls slightly compared to the base model, and the contribution of the world factor and country-specific factors are slightly higher. The redistribution of the contribution of the country-specific factor to the world factor for the United States confirms the transfer of the LTCM effects to contagion.

The model allows for cross contagion effects, with scope for contagion from the United States to Russia, and from Russia to the United States. The percentage contribution of Russian contagion to the United States is around 9 percent, and from the United States to Russia around 10.5 percent. These effects are consistent with the view that the RussianLTCM shocks reinforced each other after the original sequence of events (Kharas, Pinto and Ulatov (2001)). However, by looking at Table 5, in basis point terms the magnitudes are such 
that the effects of U.S. contagion to Russia is over 6000 basis points, whilst the transmission of Russian contagion to the United States contributes less than 1 basis point to U.S volatility.

Table 5: Volatility Decomposition with Contagion Effects from

Russia and the United States

(contribution to total volatility, in basis points)

\begin{tabular}{|c|c|c|c|c|c|}
\hline & \multirow[t]{2}{*}{ Total } & \multicolumn{4}{|c|}{ Components } \\
\hline & & World & Country & Regional & Contagion \\
\hline \multicolumn{6}{|l|}{ Industrial } \\
\hline U.S. & 7.503 & 6.838 & 0.004 & 0.000 & 0.666 \\
\hline U.K. & 13.671 & 13.822 & 0.019 & 0.000 & 0.073 \\
\hline Netherlands & 24.225 & 24.053 & 0.807 & 0.000 & 4.192 \\
\hline \multicolumn{6}{|l|}{ Eastern } \\
\hline \multicolumn{6}{|l|}{ Europe } \\
\hline Russia & 57872.003 & 52401.260 & 130.337 & 50.573 & 6199.837 \\
\hline Poland & 471.900 & 469.385 & 0.263 & 2.715 & 55.259 \\
\hline Bulgaria & 10006.001 & 9025.839 & 37.527 & 41.680 & 900.955 \\
\hline \multicolumn{6}{|l|}{ Asia } \\
\hline Indonesia & 3121.457 & 3096.893 & 8.359 & 7.941 & 8.264 \\
\hline South Korea & 820.250 & 748.769 & 43.217 & 7.490 & 20.775 \\
\hline Thailand & 499.870 & 455.843 & 3.928 & 2.735 & 37.465 \\
\hline \multicolumn{6}{|l|}{ Latin } \\
\hline \multicolumn{6}{|l|}{ America } \\
\hline Mexico & 526.703 & 523.678 & 0.017 & 0.011 & 2.997 \\
\hline Argentina & 1133.669 & 945.883 & 0.315 & 0.081 & 187.390 \\
\hline Brazil & 3515.304 & 2966.509 & 1.939 & 1.585 & 545.270 \\
\hline
\end{tabular}

As explored previously, the developing countries in this sample in general exhibit a larger degree of contagion when measured in absolute levels (basis points) than advanced economies. This is reinforced in the results for the current experiment. About 15 percent of volatility in both the Netherlands and Brazil is attributable to contagion, whilst in terms of basis points, the impact of contagion on Brazil is almost 60 times that of the impact of contagion on the Netherlands. Figures 7 and 8 show the basis points contributions of contagion for the 12 countries examined. Figure 7 presents the contributions for all economies excluding Russia, Brazil and Bulgaria which have a larger absolute volatility than other countries. These three countries are shown in Figure 8, along with Argentina, which is included in both figures as a point of reference. These figures reinforce the point that the contagion effects are larger for developing countries in general. They also show that the effects of the LTCM near-collapse do have a substantial influence on the sample. 
Figure 7: Contagion in Basis Points - The Smaller Contributions

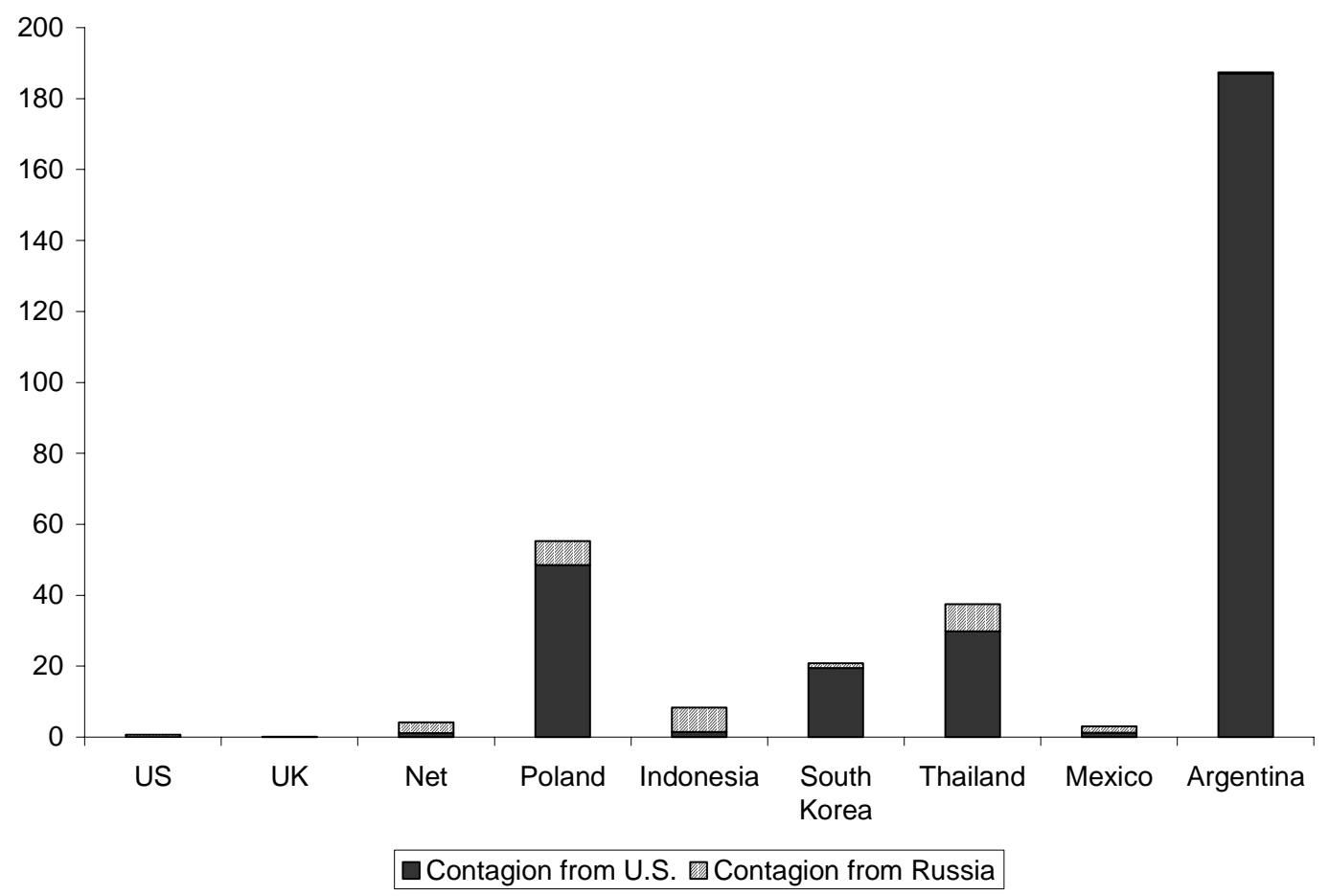

Figure 8: Contagion in Basis Points - The Larger Contributions

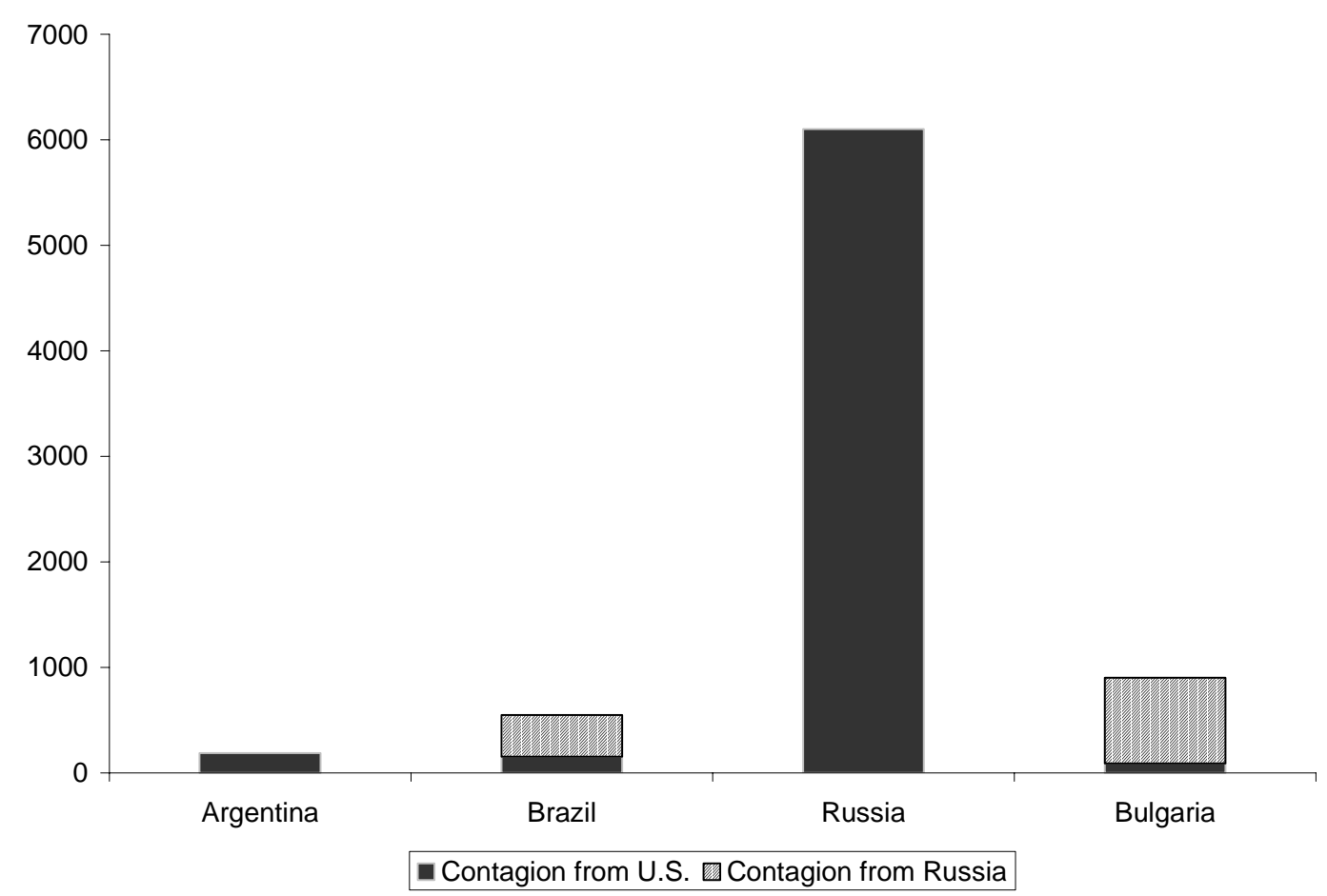


It is evident that a large proportion of contagion transmits from the Russian shock to a number of developing countries in the sample, including Brazil, Bulgaria and Indonesia. However, contagion emanating from the LTCM shock also has a relatively important effect. Contagion from the LTCM near-collapse is not confined to industrial countries, in contrast to some reports (e.g., Bank for International Settlements (1999)). In Latin America, evidence of the relative importance of the two shocks is mixed across countries. In Asia, Indonesia suffered more from the Russian shock, but Thailand and South Korea are more affected by the LTCM shock. Contagion from the United States had a smaller impact on the other industrial countries in the sample, relative to the effects of the United States on most developing countries.

Contagion emanating from the United States accounts for less than 6 percent of volatility in the Asian region, compared with a range of up to 10 percent in Eastern Europe and up to 17 percent in Latin America. The effects of the U.S. crisis on the industrial economies in the sample in percentage terms differ considerably, with less than 1 percent for the United Kingdom and 11 percent for the Netherlands. Although the effects of U.S. contagion on the industrial nations is small in basis points, the percentage contribution is not inconsistent with those presented for the other countries (e.g., Bulgaria has a similarly small contribution of total volatility stemming from U.S. contagion, while Indonesia has a comparable small effect from contagion coming from Russia). Hence, the distinction as to whether contagion hit developing and/or developed nations depends critically on whether we are interested in proportional or absolute measures.

The results for Indonesia and Brazil are worthy of further attention and future research. Indonesia drew comment during the East Asian crisis as the hardest hit by contagion effects (see for example Radelet and Sachs (1998), Goldstein, Kaminsky and Reinhart (2000)). However, the contagion effects measured here are relatively small. One hypothesis consistent with these results is that Indonesia had become extremely sensitive to global financial turmoil in general by this stage, and no longer responded to particular crises themselves. Another is that the contagion was transmitted through an alternative asset market (see for example Dungey and Martin (2001)). Disentangling these hypotheses is scope for future work.

The Brazilian results show a large proportionate effect of contagion in the final model, supporting the suspicion that Brazil suffered significant contagion in late 1998 (Baig and Goldfajn (2000)). While most of the contagion was sourced from Russia, the LTCM shock had an impact equivalent to about one-third of the size of the Russian shock. The relatively large contagion effect to Brazil may be a reflection of the vulnerability of Brazil, given that it experienced a crisis shortly after our data period ends. This hypothesis again provides scope for interesting future work in establishing at what point evidence of pre-crisis jitters are evident in financial markets data generally.

In terms of comparing the U.S. based LTCM shock and the Russian default, we are able to conclude that the Russian shock has substantial implications for an important subgroup of countries we examine here, and is not limited to developing countries. At the same 
time, contagion from the LTCM near-collapse was not confined to industrial countries. Indeed, the results suggest that these two effects may have been reinforcing each other after their initial impact. In considering the policy implications arising from financial market crises and contagion, these results suggest that we should be very clear as to the units of concern. In proportionate terms there is little to differentiate the contribution of contagion in developed and developing countries. In terms of basis points, however, the overall impact on developing countries is absolutely larger.

\section{CONCLUSION}

The international spillover effects stemming from the Russian debt default and the near-collapse of LTCM in 1998 seem to be different from those of other financial crises in the 1990s. In 1998, bond markets in both advanced and emerging economies experienced a significant widening of spreads between long-term bonds and their corresponding risk-free rate of return, or the 'premium.' In other episodes of financial crises during the 1990s, most of the impact seemed to be limited to emerging markets or even a regional subset of them.

This paper has examined the crises associated with the Russian bond default in August 1998, and the near-collapse of LTCM in September 1998. Using a latent factor model, the premium for each of the twelve markets examined is decomposed into components associated with a common world factor, a country-specific factor, a regional factor and the effects due to contagion. Contagion is defined as the contemporaneous effect of unanticipated shocks from across country borders. This definition of contagion is consistent with those offered in a substantial portion of the literature on this topic, including Masson (1999a,b,c), Favero and Giavazzi (2000) and Forbes and Rigobon (1999, 2000). The novelty of this paper is both in the application to bond markets and that we provide numerical estimates of the contribution of contagion to volatility in those markets. To our knowledge no previous estimates have been made.

The estimation results, conducted on a sample of daily data for twelve countries covering the period from February 1998 to the end of that year, show evidence of contagion from the Russian shock, as a credit risk shock, to both the developed and developing markets. In proportionate terms, contagion effects from Russia were particularly substantial for Brazil, Bulgaria, the Netherlands and the United States, and less so for Thailand and Poland. Contagion effects from the U.S. based LTCM near-collapse, as a liquidity risk shock, were also substantial for a number of countries. In proportionate terms, contagion effects from this shock were particularly important for Argentina, Russia, Poland, Thailand, Brazil and the Netherlands. These results give support to the view that the Russian-LTCM shocks reinforced each other after the original sequence of events. Contagion from both the United States and Russia together accounted for up to 17 percent of total volatility in the changes in premiums in some countries, although these effects were relatively small in others.

Our results also give support to the suspicion that Brazil was affected by contagion prior to its currency crisis in January 1999. Although most of the contagion effects to Brazil were sourced from Russia, the LTCM shock had an impact equivalent to about one-third of 
the size of the Russian shock. The relatively large contagion effects to Brazil may be a reflection of the vulnerability of this country. This hypothesis provides scope for interesting future work in establishing at what point evidence of pre-crisis jitters are evident in financial markets.

The evidence as to whether developed or developing markets were more affected by contagion was mixed when looking at the proportional contributions to volatility. What is clear from the results is that contagion, which is typically viewed as a developing country phenomenon, can also affect industrial countries. On the one hand, countries such as Poland, Brazil and Thailand were more affected by contagion than the United Kingdom but, on the other hand, Indonesia, Mexico and South Korea were less affected by contagion than the United States and the Netherlands. However, when the results are scaled by the level of the observed variance in changes in the premium for each country, it is clear that developing markets generally had a greater basis point impact from contagion effects in all cases. This largely reflects the observation that financial markets are more volatile in developing countries than in advanced economies. However, thus far it had been difficult to identify the sources of that higher volatility. In this paper, we are able to break down the main components and conclude that contagion can be an important source of volatility.

The results in this paper raise other interesting questions for further research. In particular, it seems useful to investigate which measure of contagion is more important to economies: the proportion of total volatility affected by contagion or the absolute level of the contagion effect (measured here in basis points). The two measures can lead to different policy conclusions. If the most meaningful measure of contagion is given by the proportional effects to volatility, then contagion is an issue of interest for both developing countries and advanced economies. Otherwise, contagion is an issue of interest mostly for developing countries. Most of the literature on contagion seems to espouse the notion that contagion is only a concern for developing countries but the results in this paper suggest that this is not necessarily the case. 


\section{References}

Bae, K.H., G.A. Karyoli and R.M. Stultz (2000) "A New Approach to Measuring Financial Contagion,” NBER Working Paper 7913.

Baig, T. and I. Goldfajn (2000), "The Russian Default and the Contagion to Brazil," IMF Working Paper WP/00/160, October.

Baig, T. and I. Goldfajn (1998), "Financial Market Contagion in the Asian Crisis," IMF Working Paper 98/155.

Bank for International Settlements (1999), "A Review of Financial Market Events in Autumn 1998," Committee on the Global Financial System, Basel, Switzerland, October.

Bollerslev, T., R.Y. Chou, and K.F. Kroner (1992), “ARCH Modeling in Finance: A Review of the Theory and Empirical Evidence," Journal of Econometrics, 52(1-2), 5-59.

Calvo, G.A. and E.G. Mendoza, (2000), "Rational Contagion and the Globalization of Securities Markets," Journal of International Economics, 51(1), 79-113.

Diebold, F.X. and M. Nerlove (1989), "The Dynamics of Exchange Rate Volatility: A Multivariate Latent-Factor ARCH Model," Journal of Applied Econometrics, 4, 1-22.

Dooley, M.P. (2000), “A Model of Crises in Emerging Markets,” Economic Journal, 110(46), 256-72.

Dornbusch, R., Y.C. Park, and S. Claessens (2000), "Contagion: Understanding How It Spreads," World Bank Research Observer, 15(2), 177-97.

Duffie, D. and K. Singleton (1993), "Simulated Moments Estimator of Markov Models of Asset Prices," Econometrica, 61, 929-62.

Dungey, M. (1999), "Decomposing Exchange Rate Volatility Around the Pacific Rim," Journal of Asian Economics, 10, 625-35.

Dungey, M. and V.L. Martin (2000), "Measuring Contagion in the East Asian Currency Crisis," mimeo, Australian National University.

Dungey, M. and V.L. Martin (2001), “Contagion Across Financial Markets: An Empirical Assessment,” New York Stock Exchange Conference Paper, 16-17 February, 2001, Hawaii.

Dungey, M., R. Fry and V.L. Martin (2001), "Currency Market Contagion in the AsianPacific Region," mimeo, University of Melbourne. 
Dungey, M., V.L. Martin and A.R. Pagan (2000), "A Multivariate Latent Factor Decomposition of International Bond Yield Spreads," Journal of Applied Econometrics, 15(6), 697-715.

Edwards, S. (2000), “Interest Rates, Contagion and Capital Controls,” NBER Working Paper, 7801.

Eichengreen, B., A.K. Rose and C. Wyplosz (1995), "Exchange Market Mayhem: The Antecedents and Aftermath of Speculative Attacks," Economic Policy, 21, 249-312.

Eichengreen, B., A.K. Rose and C. Wyplosz (1996), “Contagious Currency Crises,” NBER Working Paper, 5681.

Ellis, L. and E. Lewis (2000), “The Response of Financial Markets in Australia and New Zealand to News about the Asian Crisis," BIS Conference on International Financial Markets and the Implications for Monetary and Financial Stability, Basle, 25-26 October, 1999, Vol.8.

Favero, C.A. and F. Giavazzi (2000), "Looking for Contagion: Evidence from the ERM," NBER Working Paper, 7797.

Forbes, K. (2000), “The Asian Flu and Russian Virus: Firm-Level Evidence on How Crises are Transmitted Internationally," Mimeograph, MIT-School of Management and NBER.

Forbes, K. and R. Rigobon (1999), "No Contagion, Only Interdependence: Measuring Stock Market Co-Movements,” NBER Working Paper, 7267.

Forbes, K. and R. Rigobon (2000), "Measuring Contagion, Conceptual and Empirical Issues," mimeo, MIT.

Gallant, A.R. and G. Tauchen (1996), "Which Moments to Match?," Econometric Theory, 12 (4), 657-81.

Glick, R. and A.K. Rose (1999), "Contagion and Trade: Why are Currency Crises Regional?," Journal of International Money and Finance, 18(4), 603-17.

Goldstein, M. (1998), “The Asian Financial Crisis: Causes, Cures and Systemic Implications," Policy Analysis in International Economics, 55, Institute for International Economics, Washington D.C.

Goldstein, M., G.L. Kaminsky and C.M. Reinhart (2000), “Assessing Financial Vulnerability: An Early Warning System for Emerging Markets, ” Institute for International Economics, Washington D.C. 
Gourieroux, C. and A. Monfort (1994), Simulation Based Econometric Methods, CORE Discussion Paper.

Gourieroux, C., A. Monfort and E. Renault (1993), “Indirect Inference,” Journal of Applied Econometrics, 8, S85-S118.

Gregory, A.W. and D.G. Watts (1995), "Sources of Variation in International Real Interest Rates," Canadian Journal of Economics, 18, S120-S140.

International Monetary Fund (1999), World Economic Outlook: International Financial Contagion, May 1999, International Monetary Fund, Washington D.C.

Jorion, P. (2000), “Risk Management Lessons from Long-Term Capital Management,” European Financial Management, 6, September, pp. 277-300.

JP Morgan (1999), “Introducing our New Liquidity and Credit Premia Update,” August.

Kaminsky, G.L. and C.M. Reinhart, (2000), "On Crises, Contagion and Confusion,” Journal of International Economics, 51(1), 145-68.

Kaminsky, G.L. and S.L. Schmukler, (1999), "What Triggers Market Jitters? A Chronicle of the Asian Crisis," Journal of International Money and Finance, 18(4), 537-60.

Kharas, H., B. Pinto and S. Ulatov (2001), “An Analysis of Russia’s 1998 Meltdown: Fundamentals and Market Signals," Brookings Papers on Economic Activity, Brookings Institution, 1 pp.1-68.

King, M., E. Sentana and S. Wadhwani (1995), "Volatility and Links Between National Stock Markets," Econometrica, 62, 901-33.

Kose, M.A., C. Otrok and C. Whiteman (1999), "International Business Cycles: World, Region and Country-Specific Factors," manuscript, University of Iowa.

Kruger, M., P.N. Osakwe, and J. Page, (1998), "Fundamentals, Contagion and Currency Crises: An Empirical Analysis,” Bank of Canada Working Paper \#98-10.

Krugman, P. (1998), "What Happened to Asia?," mimeo, MIT.

Kumar, Manmohan and Avinash Persaud (2001), "Pure Contagion and Investors' Shifting Risk Appetite: Analytical Issues and Empirical Evidence," forthcoming Working Paper, International Monetary Fund.

Kyle, A.S. and Wei X. (2001), "Contagion as a Wealth Effect," The Journal of Finance, LVI(4), 1401-1440 
Loisel, O. and P. Martin, (2001), "Coordination, Cooperation, Contagion and Currency Crises," Journal of International Economics, 53, 399-419.

Lowell, J., C.R. Neu and D. Tong, (1998) "Financial Crises and Contagion in Emerging Market Countries,” RAND, MR-962.

Mahieu, R. and P. Schotman (1994), "Neglected Common Factors in Exchange Rate Volatility," Journal of Empirical Finance, 1, 279-311.

Masson, P. (1999a), "Contagion: Macroeconomic Models With Multiple Equilibria," Journal of International Money and Finance, 18, 587-602.

Masson, P. (1999b), “Contagion: Monsoonal Effects, Spillovers, and Jumps Between Multiple Equilibria," in Agenor, P.R., M. Miller, D. Vines, and A. Weber, (eds), The Asian Financial Crisis: Causes, Contagion and Consequences, Cambridge University Press, Cambridge, U.K..

Masson, P. (1999c), "Multiple Equilibria, Contagion and the Emerging Market Crises," IMF Working Paper \#99/164.

Ng, V.K., R.F. Engle and M. Rothschild (1992), “A Multi-Dynamic Factor Model for Stock Returns," Journal of Econometrics, 52, 245-66.

Radelet, S. and J.Sachs (1998), "The Onset of the East Asian Financial Crisis," mimeo, Harvard Institute for International Development.

Reside, R.E. and M.S. Gochoco-Bautista (1999), "Contagion and the Asian Currency Crisis," The Manchester School, 67(5), 460-74.

Rigobon, R. (2001), “Contagion: How to Measure It?,” NBER Working Paper 8118.

Sachs, J., A. Tornell and A. Velasco (1996), "Financial Crises in Emerging Markets: The Lessons from 1995," Brookings Papers on Economic Activity, 1, 146-215.

Van Rijikeghem, C.V., and B. Weder (2001), "Sources of Contagion: Is it Finance or Trade," Journal of International Economics, 54, 293-300.

Wirjanto, T.S. (1999), "Empirical Indicators of Currency Crises in East Asia," Pacific Economic Review, 4(2), 165-83. 


\section{A. Data Definitions and Sources}

Argentina: Republic of Argentina bond spread over U.S. Treasury.

Source: U.S. Federal Reserve.

Brazil: Republic of Brazil bond spread over U.S. Treasury.

Source: U.S. Federal Reserve.

Mexico: JP Morgan Eurobond Index Mexico Sovereign spread over U.S. Treasury. Source: U.S. Federal Reserve.

Indonesia: Indonesian Yankee Bond Spread over U.S. Treasury.

Source: U.S. Federal Reserve.

South Korea: Government of Korea 8 7/8\% 4/2008 over U.S. Treasury.

Source: Bloomberg (50064FAB0)

Thailand: Kingdom of Thailand Yankee Bond Spread over U.S. Treasury.

Source: U.S. Federal Reserve. (The longer series used in Figure 1, dating back to 1997, comes from Credit Swiss First Boston).

Bulgaria: Bulgarian Discount Stripped Brady Bond Yield Spread over U.S. Treasury. Source: U.S. Federal Reserve.

Poland: Poland Par Stripped Brady Bond Yield Spread over U.S. Treasury.

Source: U.S. Federal Reserve.

Russia: Government of Russia 9.25\% 11/2001 over U.S. Treasury.

Source: Bloomberg (007149662).

Netherlands: Akzo Nobel NV 8\% 12/2002 yield spread over NETHER 8.25\% 6/2002.

Source: U.S. Federal Reserve.

United Kingdom: U.K. Industrial BBB Corporate 5-year Bond Spread over Gilt.

Source: Bloomberg (UKBF3B05)

United States: U.S. Industrial BBB1 Corporate 10-year Bond Spread over U.S.

Treasury. Source: Bloomberg (IN10Y3B1) 


\section{B. Data Used for Empirical Estimation and Missing Observations}

The data period on which the econometric estimation was based runs from February 12 to December 31,1998 . The data are daily, the start period is constrained by the availability of a consistent data set on the Thai bonds (earlier observations in the extended data set used in Figure 1 are only for two or three days during each week). The bond spreads, or "risk premiums," are constructed by taking a representative longterm sovereign bond issued in U.S. dollars by an emerging country and subtracting from it a U.S. Treasury bond of comparable maturity. For advanced economies, the risk premiums are constructed by taking a representative long-term corporate bond in domestic currency and subtracting from it a government Treasury bond of comparable maturity.

The data points for which there were any missing observations in any of the series had to be removed from all other series in order to keep the daily observations consistent. After removing from the original sample of 231 observations the missing observations, the empirical analysis was based on the remaining 209 observations in the sample. The series with the largest number of missing observations is the Polish data, which had 17 missing observations. 
Table I. 1: Missing Data for the Contemporaneous Date Series ${ }^{1}$

\begin{tabular}{ccl}
\hline Day & Month & Missing Series \\
\hline 16 & Feb & Argentina, Brazil, Mexico, Bulgaria, Poland, U.S. \\
12 & Mar & Bulgaria, Poland \\
20 & Mar & Bulgaria, Poland \\
1 & Apr & Bulgaria, Poland \\
3 & Apr & U.K. \\
10 & Apr & Argentina, Brazil, Mexico, Bulgaria, Poland, U.K., U.S. \\
13 & Apr & U.K. \\
20 & Apr & Bulgaria, Poland \\
21 & Apr & Bulgaria, Poland \\
4 & May & U.K. \\
7 & May & U.K. \\
12 & May & Bulgaria, Poland \\
25 & May & Argentina, Brazil, Mexico, Bulgaria, Poland,U.K., U.S. \\
3 & July & Bulgaria, Poland, Mexico, U.S. \\
15 & July & Poland \\
16 & July & Poland \\
31 & Aug & U.K. \\
7 & Sep & Bulgaria, Poland, Mexico, U.S. \\
12 & Oct & Mexico, U.S. \\
11 & Nov & Mexico, U.S. \\
26 & Nov & Bulgaria, Poland, Mexico, U.S. \\
1 & Dec & Thailand \\
25 & Dec & Argentina, Brazil, Mexico, Bulgaria, Poland, Thailand, U.K., \\
& & U.S. \\
\hline
\end{tabular}

Table I. 2. Total Number of Missing Observations by Country:

\begin{tabular}{lclc}
\hline Country & Missing observations & Country & Missing observations \\
\hline USA & 9 & Argentina & 5 \\
U.K. & 10 & Brazil & 5 \\
Netherlands & 0 & Mexico & 12 \\
Russia & 0 & Indonesia & 0 \\
Bulgaria & 16 & Thailand & 4 \\
Poland & 17 & South Korea & 0 \\
\hline
\end{tabular}

\footnotetext{
${ }^{1}$ This details the missing observations we could identify in the database - there were cases where there was no trading on a particular day in the country, which is not shown in the list because observations were not clearly designated as missing (for example the common practice of repeating the previous day's observation was observed in some series, making it more difficult to clean; an example is the Netherlands observation for Christmas day).
} 
Table II.1: Descriptive Statistics of Premiums (in levels)

\begin{tabular}{|c|c|c|c|c|c|c|}
\hline \multirow[b]{2}{*}{ Statistic } & \multicolumn{3}{|c|}{ Industrial Countries } & \multicolumn{3}{|c|}{ Eastern Europe } \\
\hline & U.S. & U.K. & Netherlands & Russia & Poland & Bulgaria \\
\hline Mean & 106.06 & 122.92 & 58.59 & 2871.81 & 261.21 & 951.72 \\
\hline Maximum & 153.00 & 203.00 & 109.10 & 6825.78 & 521.00 & 2279.00 \\
\hline Minimum & 67.00 & 76.00 & 34.20 & 392.35 & 162.00 & 535.00 \\
\hline Std. Dev. & 28.85 & 36.26 & 20.38 & 2512.65 & 75.73 & 431.92 \\
\hline $\mathrm{AR}(1)$ & 0.99 & 0.99 & 0.96 & 0.99 & 0.95 & 0.97 \\
\hline $\operatorname{AR}(2)$ & 0.98 & 0.98 & 0.93 & 0.98 & 0.90 & 0.94 \\
\hline Skewness & 0.44 & 0.72 & 0.95 & 0.28 & 0.95 & 1.35 \\
\hline Kurtosis & 1.38 & 2.03 & 2.42 & 1.20 & 3.17 & 4.26 \\
\hline \multirow{3}{*}{$\begin{array}{l}\text { Jarque-Bera } \\
\text { ( } \mathrm{p} \text { value) }\end{array}$} & 29.51 & 26.11 & 34.24 & 30.96 & 31.53 & 77.52 \\
\hline & \multicolumn{3}{|c|}{ Asia } & \multicolumn{3}{|c|}{ Latin America } \\
\hline & Indonesia & S. Korea & Thailand & Mexico & Argentina & Brazil \\
\hline Mean & 959.67 & 486.26 & 423.17 & 469.70 & 534.70 & 744.07 \\
\hline Maximum & 1865.80 & 965.88 & 916.30 & 868.33 & 1061.00 & 1438.00 \\
\hline Minimum & 537.10 & 306.70 & 270.20 & 297.66 & 374.00 & 415.00 \\
\hline Std. Dev. & 369.50 & 163.88 & 167.48 & 155.61 & 140.62 & 291.13 \\
\hline $\mathrm{AR}(1)$ & 0.99 & 0.98 & 0.99 & 0.99 & 0.97 & 0.98 \\
\hline $\operatorname{AR}(2)$ & 0.97 & 0.96 & 0.98 & 0.97 & 0.94 & 0.96 \\
\hline Skewness & 0.97 & 1.26 & 1.16 & 0.66 & 1.26 & 0.61 \\
\hline Kurtosis & 2.58 & 3.84 & 3.32 & 2.16 & 4.38 & 2.12 \\
\hline Jarque-Bera & 34.05 & 61.44 & 47.79 & 21.10 & 71.84 & 19.71 \\
\hline (p value) & $(0.000)$ & $(0.000)$ & $(0.000)$ & $(0.000)$ & $(0.000)$ & $(0.000)$ \\
\hline
\end{tabular}


Table II.2: Descriptive Statistics of Change in the Premiums

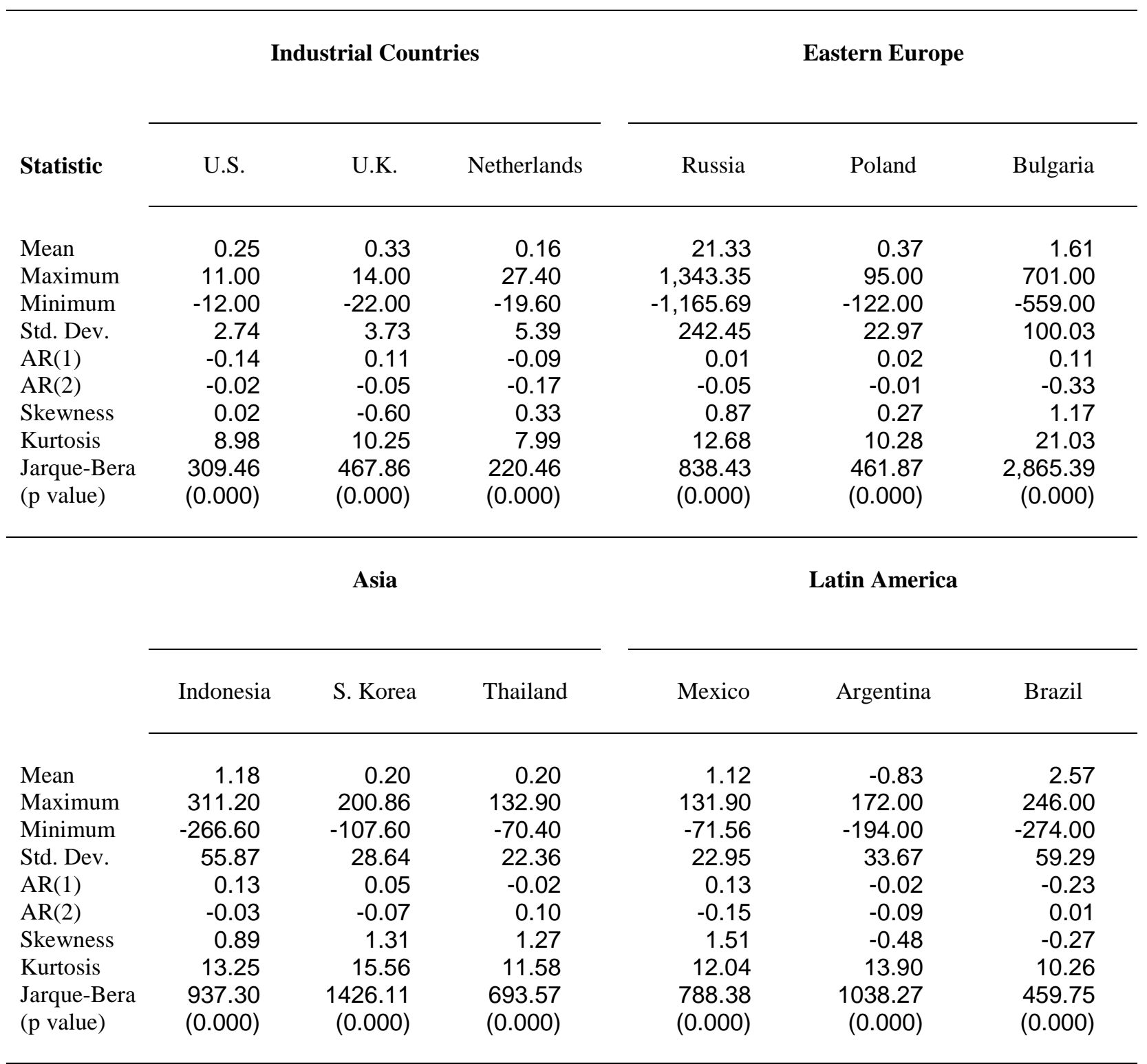


Table II.3: Augmented Dickey Fuller and Phillips Perron Unit Root Tests of the Premiums

\begin{tabular}{lcc}
\hline \multicolumn{1}{c}{ Premium } & ADF Test & Phillips Perron Test \\
\hline & & \\
Argentina & -1.700 & -1.818 \\
Brazil & -1.138 & -1.283 \\
Mexico & -1.183 & -1.273 \\
Indonesia & -1.219 & -1.216 \\
South Korea & -1.302 & -1.433 \\
Thailand & -1.129 & -1.081 \\
Bulgaria & -1.379 & -1.685 \\
Poland & -2.287 & -2.299 \\
Russia & -0.727 & -0.741 \\
Netherlands & -1.256 & -1.540 \\
U.S. & -0.602 & -0.641 \\
U.K. & -0.605 & -0.577
\end{tabular}

MacKinnon critical values for rejection of the hypothesis of a unit root for the ADF test are: $1 \%$ critical value -3.4634 ( ${ }^{*}$ represents rejection at the $1 \%$ level of significance) $5 \%$ critical value -2.8756 (** represents rejection at the $5 \%$ level of significance) MacKinnon critical values for rejection of the hypothesis of a unit root for the PP test are: $1 \%$ critical value -3.4631 ( ${ }^{*}$ represents rejection at the $1 \%$ level of significance) $5 \%$ critical value -2.8755 ( ${ }^{* *}$ represents rejection at the $5 \%$ level of significance)

Table II.4: Johansen Cointegration Test of the Premiums

\begin{tabular}{lcccc}
\hline $\begin{array}{c}\text { Hypothesized } \\
\text { No. of CE(s) }\end{array}$ & Eigenvalue & $\begin{array}{c}\text { Trace } \\
\text { Statistic }\end{array}$ & $\begin{array}{c}\text { 5 Percent } \\
\text { Critical Value }\end{array}$ & $\begin{array}{c}\text { 1 Percent } \\
\text { Critical Value }\end{array}$ \\
\hline None & 0.403 & 493.531 & NA & NA \\
At most 1** & 0.324 & 386.832 & 277.71 & 293.44 \\
At most 2** & 0.272 & 305.882 & 233.13 & 247.18 \\
At most 3** & 0.252 & 240.302 & 192.89 & 204.95 \\
At most 4** & 0.196 & 180.140 & 156.00 & 168.36 \\
At most 5** & 0.150 & 135.047 & 124.24 & 133.57 \\
At most 6* & 0.137 & 101.417 & 94.15 & 103.18 \\
At most 7* & 0.127 & 70.936 & 68.52 & 76.07 \\
At most 8 & 0.072 & 42.728 & 47.21 & 54.46 \\
\hline
\end{tabular}

$\left.{ }^{*}{ }^{* *}\right)$ denotes rejection of the hypothesis at the $5 \%(1 \%)$ significance level.

Trace statistic indicates 8 cointegrating equations at the $1 \%$ significance level 